\title{
WestVirginiaUniversity
}

THE RESEARCH REPOSITORY @ WVU

Graduate Theses, Dissertations, and Problem Reports

2005

\section{How people become media literate and their media habits}

Indira Liz Calles Giraud

West Virginia University

Follow this and additional works at: https://researchrepository.wvu.edu/etd

\section{Recommended Citation}

Calles Giraud, Indira Liz, "How people become media literate and their media habits" (2005). Graduate Theses, Dissertations, and Problem Reports. 1584.

https://researchrepository.wvu.edu/etd/1584

This Thesis is protected by copyright and/or related rights. It has been brought to you by the The Research Repository @ WVU with permission from the rights-holder(s). You are free to use this Thesis in any way that is permitted by the copyright and related rights legislation that applies to your use. For other uses you must obtain permission from the rights-holder(s) directly, unless additional rights are indicated by a Creative Commons license in the record and/ or on the work itself. This Thesis has been accepted for inclusion in WVU Graduate Theses, Dissertations, and Problem Reports collection by an authorized administrator of The Research Repository @ WVU. For more information, please contact researchrepository@mail.wvu.edu. 
How people become media literate and their media habits

\author{
by \\ Indira Liz Calles Giraud
}

\begin{abstract}
A Thesis Submitted to the Faculty of the Perley Isaac Reed School of Journalism at West Virginia University in partial fulfillment of the requirements for the degree of
\end{abstract}
Master of Science
in
Journalism
Terry Wimmer, Ph.D., Chair Ivan Pinnell, Ph.D.
Phylissa D. Mitchell, J.D.
Carol Zwickel, Ph.D.

Perley Isaac Reed School of Journalism

\author{
Morgantown, West Virginia \\ 2005
}




\section{ABSTRACT \\ How people become media literate and their media habits \\ Indira Liz Calles Giraud}

Media literacy is defined as the way people analyze and interpret messages from mass media. This project studies how people become media literate and methodologies that may be applied to make media education more effective. It is important to know and understand background information about people, exclusively their likes and dislikes about mass media and also to identify what makes these people form media literacy habits. This study discusses different theories about media education and propagation. But primarily this study compares those who have had formal exposure to media literacy with those whose exposure has been less methodical. The study hypothesizes and proves that those who started their media education in elementary school are more critical thinkers than those who started their media education later, the former are also more frequent users of media. 


\section{Table of Contents}

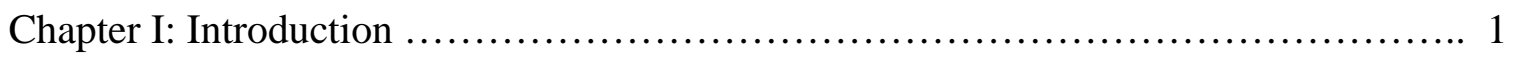

Chapter II: Research question................................................. 3

Chapter III: Literature Review.....................................................

Chapter IV: Research Hypothesis............................................36

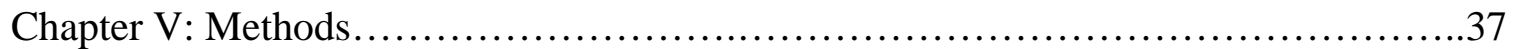

Chapter VI: Results and Discussions.......................................38

Chapter VII: Conclusion.................................................... 46

Chapter VIII: Bibliography...............................................48

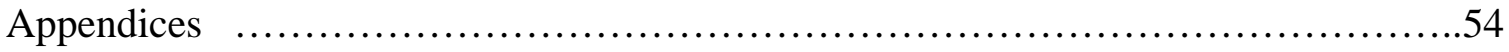




\section{INTRODUCTION}

Communication is usually between human beings with face-to-face messages by using verbal and nonverbal symbols. The act of human communication began with a sender with a specific message that was transmitted, spoken or written, later it was received by an individual. In ancient times people used to communicate in this way. Rural life in the farms and mountains was the only lifestyle that existed for people. ${ }^{1}$ Modernization and new technologies facilitated movement and information in communities. This innovation included development of transportation, such as all weather roads and canals. Years later, the creation of the telegraph and the telephone changed the way people communicated. The Industrial Revolution began in the 1900s and the methods of communication between changed and made communication more advanced with the incorporation of newspapers, magazines, and radio. ${ }^{2}$

When the media literacy movement began in 1970, it was widely considered a waste of time. Why focus on ads, television, and movies, the thinking went, when what students really need is to learn the fundamental subjects at school? It is very important to explain the meaning of mass media and literacy and how mass media functions in the industry and our society. ${ }^{3}$

\footnotetext{
${ }^{1}$ Melvin DeFleur and Dennis Everette, Understanding Mass Communication, (Boston: Houghton Mifflin Company, 1994), 1-10.

${ }^{2}$ Lawrence Grossberg, Ellen Wartella and D. Charles Whitney, Media Making: Mass Media in a popular Culture, (London: Sage Publications, 1998), 16.

${ }^{3}$ David Considine, “Media Literacy: National Developments and International Origins,” Journal of Popular Film and Television (Spring 2002): 2.
} 
Mass media came to change the way people communicate in society. The newspaper came to change the way people knew about news. This medium became the main provider of serious information about political, social, and economical situation.

The newspaper was also a local medium for audiences and advertisers. Magazines came to be incorporated into society as a complement of the newspaper. At the beginning, this medium had the role to publish general information about health, education, politics, economy and sociology. Magazines like Forbes and Newsweek changed the conception of magazines, as they were an enterprise with good editorials. ${ }^{4}$

Film and television introduced new images and sounds projected on screen. Today the film industry is well established and many companies have their own theaters. The production and export of films to foreign countries is very good business as is importing movies for viewing in the United States from other parts of the world. Television has been through the years the primary source of information and entertainment with programs of all categories: drama, comedy, suspense, and education. In addition, cable television created a revolution in broad electronic media. Cable in mass media broadcasts a wider perspective about television, because of the transmission of international programs. This also changed the way people saw television and helped society become more cultural and have a broader perspective about the world. ${ }^{5}$

Computers have also changed the way people communicate. Previously people could only use telegraph and letters to send messages from one place to another. When computers and Internet were integrated in the world, chats and e-mail replaced the old methods of communication. These days, people know more about news, products, and

\footnotetext{
${ }^{4}$ Ibid., 185-190.

${ }^{5}$ Ibid., 190-191.
} 
services from the Internet. There are millions of web pages and sites that provide the public with all kind of information. ${ }^{6}$

\section{RESEARCH QUESTION}

How has the media literacy movement helped people to form a better understanding of the messages that come from media?

\section{LITERATURE REVIEW}

Cultural historians normally recognize that a time gap occurs between the moment when a new medium is invented and the age when a literate community finally emerges to create a more complete understanding of that technology's full potential. From the early to the high Renaissance, for example, literary knowledge and training were the domain of clergy and noble. The printing press eventually gave rise to a public universal concept of oral, written, and reading literacy that continues to flourish worldwide even today. Media literacy first surfaced as a concept-in-progress during the first few decades of the twentieth century embedded in the film theories of artists and scholars such as Vachel Lindsay, Hugo Munsterberg, and Rudolf Arnheim, who applied his training in gestalt psychology to art, motion pictures, and even TV while this experimental medium was still largely restricted to the laboratory. ${ }^{7}$

More sophisticated studies by Marshall McLuhan, Walter Ong, and James Carey that came of age after World War II began to explore writings about the emerging presence of a media environment and how it was transforming the way people conducted their home life, work, and leisure time, participate as citizens and consumers, and understand the image-saturated world that envelops us. Over the next generation,

\footnotetext{
${ }^{6}$ Ibid.

${ }^{7}$ Nicholas Cull, “Introduction,” Historical Journal of Film, Radio and Television (August 2000): 227.
} 
communication as a discipline and media studies as a specialty became institutionalized in colleges and universities, especially in the United States, Canada, Europe, and Australia, where an internationally literate community now teaches and generates its own scholarly literature on the history, theory, relevant issues, and skills necessary for a maturing media literacy perspective. These developments come from the study of communication; cultural studies education, television and film. Media literacy studies the diversity of the mass media and has the purpose of linking mass media and literacy in the school curriculum. ${ }^{8}$

The broadly accepted American, even North American, definition of media literacy states that, "it is the ability to decode, analyze, evaluate and produce communication in a variety of forms" ${ }^{9}$ For other scholars like Aufderheide believe media literacy "is the ability of a citizen to access, analyze, evaluate and produce information for specific outcomes” through various means of communication. ${ }^{10}$ Thoman claims that media literacy is the ability to create personal meaning from the verbal and visual symbols we take in every day through television, radio, computers, newspapers and magazines, and of course, advertising. The ability to be conscious about what's going on around us means intentional reflection on the media themselves. ${ }^{11}$ The media is not simply transmissions it is about life on earth, society, and individual happiness. ${ }^{12}$ Media

\footnotetext{
${ }^{8}$ Ibid.

${ }^{9}$ David M. Considine “Media Literacy: National developments and International Origins,” Journal of Popular Film \& Television (spring 2002): 7-9.

${ }^{10}$ Patricia Aufderheide, "Media Literacy: Forum Report,”(paper presented at the National Leadership Conference on Media Literacy, Queenstown, MD, December, 1991): 2.

${ }^{11}$ Elizabeth Thoman, "Skill and Strategies for Media Education,” Educational Leadership 56 (February 1999): 50 .

${ }^{12}$ Gretchen Schwarz, “Renewing the Humanities Through Media Literacy,” Journal of Curriculum and Supervision (Fall 2003): 44-53.
} 
literacy analysis and evaluation of messages in the media can motivate students to challenge their ideas about literature, culture and other topics presented by the mass media. Media literacy provides the students with the opportunity to discover new issues and knowledge about media. ${ }^{13}$ The center for Media Literacy in New York defines media literacy as the capacity of communicating information through print or electronic means and the people's ability to analyze images, words and sounds and how it helps them to interpret real messages and have a better understanding of ideas. ${ }^{14}$

James Potter conceived and analyzed media literacy and how this is developed. Media literacy is the perspective from which we expose ourselves to the media and interpret the meanings of the messages we encounter. We build this perspective from knowledge structures. To build our knowledge structure, we need tools and unprocessed material. The tools are our skills; the untreated material is information from the media and from the real world. ${ }^{15}$

Media literacy cannot be limited. A person is never going to be cultural and literate enough to take in all messages that media provides. There is always space for improvement in the media literacy world. ${ }^{16}$

Media literacy is dependant on the sophistication of the person receiving the messages. People with less evolved understanding of messages accept all the commercial, television shows and movies in a positive way, without analyzing the content of each message presented by the media. However those with a greater capacity to process messages analyze them in a very different way. However these are still imperfect because

\footnotetext{
13 Ibid.

${ }^{14}$ Royal Van Horn, “Sex, Potato Chips, and Media Literacy,” Journal of Technology (September 2002): 2.

${ }^{15}$ James Potter, Media Literacy, 5-11.

16 Ibid.
} 
they do not process messages in a meaningful way. They must also be able to catch all the pros and cons of the messages transmitted across different media. When people through the years learn about media and have a more complete comprehension of the messages, they really are able to interpret and actively process messages. It is crucial to catch up with the ideas and messages that media present because daily media present different kind of information. ${ }^{17}$

In understanding the meaning of media messages, there are four categories. The first one is the cognitive domain in which people put in practice their mental processes and thinking. Here people prove their understanding about how a message is produced and why is presented in that way. The second category is the emotional domain. Here people link their feelings and emotions with the messages presented on television, radio, newspapers, and Internet. Emotional domain does not require a high degree of literacy. The third one is the aesthetic, here people prove their ability to like, comprehend and realize media content from an artistic perspective. Finally, the moral domain provides the analysis of values present in the messages. ${ }^{18}$

Media literacy provides us with enough skill to interpret the message. Journalists, advertisers and entertainers give us their own interpretations about news, the behavior of the human being, how conflicts are present and how to achieve success. These give society an idea on how to construct their interpretations of the messages. ${ }^{19}$

In the process fundamental to the understanding ideas of media literacy, it is important to recognize and analyze the messages received from the media. The

\footnotetext{
${ }^{17}$ Ibid.

${ }^{18}$ Ibid.

${ }^{19}$ Ibid.
} 
development of a high level of media literacy increases the control over the media influence process. $^{20}$

Education is essential to media literacy because of the importance of learning to understand the messages with being educated facilitates. Technology is another important part of learning messages. In addition sociology is fundamental as a part of understanding the behavior of the human beings and how people perceive messages and the role of politics in mass media and its influence on people. It is crucial to explain how media literacy is connected with each of these aspects:

Media education emerged during the 1970s and 80's as a result of the contribution of semiotics and theories of ideology. It changed the emphasis of media from matters of taste or aesthetics, which previously was the focus of media literacy. Media education now borrowed from new sources and began to ask new questions. It is also important to know the relation between people and media. What relationships were at work in the process? Whose visions and voices were seen and heard, and whose were silenced? These questions ultimately generated a central principle of media education evident today in all western nations working in this field. That concept is "the principle of nontransparency."21 This principle explained media as reflections of reality and construction of messages. In fact, says Masterman, the idea of media representations has become "the dominant concept of media education."22 Within the United States, evidence of this focus can be located in the literature of both mass media and education. ${ }^{23}$

\footnotetext{
${ }^{20}$ Art Silverblatt, “Media Literacy: Keys to interpreting media messages,” (Westport, Conn: Praeger, 2001$), 30$.

${ }^{21}$ Ibid.

22 Ibid.

${ }^{23}$ David M. Considine “Media Literacy: National developments and International Origins,” Journal of Popular Film \& Television (spring 2002): 7-9.
} 
Media education represents a big challenge for teachers as well as students. Teachers have the responsibility of giving students necessary tools to develop an understanding about how the messages are structured and perceived. The combination of mass media and literacy play a very important role on how people interpret messages and makes an analysis on print literacy from the understanding of a message. Does the analysis of the messages help students to figure out the meaning of a text? What is the perception of this message? How are stereotypes, archetypes and prospects created? ${ }^{24}$

Media literacy changes the way teachers teach. The relationship between teacher and student and between the reader and lessons taught play a fundamental part here. By understanding how stories are told to us we become capable of realizing our connection with the media and the institutions that make and present these stories. ${ }^{25}$

When students are exposed to media like newspaper, soap operas etc... They can discover how the meanings of these well-constructed descriptions are communicated with the purpose of obtaining social control. Nevertheless, students are active participants in receiving, constructing, reflecting and interpreting messages. ${ }^{26}$

Education in media literacy gives the ability to analyze messages from media and gives high school and university students the chance of understanding themselves and others. Through media related classroom activity students will get the understanding needed to begin to understand why media needs to be confronted. The connection

\footnotetext{
${ }^{24}$ Lesley L. Johnson, Media, Education and Change (New York: Peter Lang Publishing, Inc., 2001), 9-15.

${ }^{25}$ Ibid.

${ }^{26}$ Ibid.
} 
between media related classroom activities and reasoning activities should be explained by teachers. ${ }^{27}$

One very important issue is that everybody has personal biases. It is important to keep in mind that the process of pedagogy should involve confronting these issues and biases, hence allowing all voices participating in the process to be heard. ${ }^{28}$

Nowadays, media literacy education in middle schools generally emphasizes one of three approaches. There is value in each approach and, of course, in classroom practice the approaches often overlap or are combined. ${ }^{29}$

One approach is to help students understand the structure the media they encounter. This approach of treating electronic popular media such as television as a valid form of communication requires the familiarity and skill to read and interpret this kind of media. Asking students to cautiously read television programs and to understand the symbolic and poetic elements that allow viewers to make sense of what they are seeing and hearing. Students are asked to read electronic media much as they are asked to read printed texts and to focus on similar point of view, narratives, plots, characters and so on. Students might be asked to think of television in terms of the audience for whom a program is designed and when it is broadcast. Analysis of television composition and editing helps us read and interpret electronic visual texts. ${ }^{30}$ Film and programs produced

\footnotetext{
${ }^{27}$ Ibid.

${ }^{28}$ Ibid., 15-16.

${ }^{29}$ Bronwyn T. Williams, "What they see and is what we get: Television and middle school writers," Journal of Adolescent \& Adult Literacy (April: 2003): 2-6.

${ }^{30} \mathrm{Ibid}$.
} 
with the same techniques as films are often included in this approach as the two media often overlap in this approach to media literacy. ${ }^{31}$

This approach has a great deal of value. Students understand that the television programs they watch have a specific structure. They also realize how much they have already learned about media literacy from the ways in which they can read television texts. $^{32}$ Students become more sophisticated and empowered readers of television and this in turn gives a sense of empowerment. Studies show that the enthusiasm the students showed in discussing films also applies to such classroom discussions about television. When teachers can get their students fully involved in a lesson, they know they have done their job. The particular skills predicting, responding, questioning, and visualizing, are ones that students at any level need either to develop or to practice media education. ${ }^{33}$

The emphasis on media literacy focuses exclusively on electronic mass media and how experiences and skills from watching television programs are related to print. Still such subject matter is not unusual pertain to the study popular media. There is a connection between various ways of communicating and to ignore any form of media is to deny students the opportunity to experiment and explore how different media are connected. The media literacy approach also does not help students investigate the cultural, economical and political forces that influence how the structures of television are created and distributed. ${ }^{34}$

\footnotetext{
${ }^{31}$ Ibid.

${ }^{32}$ Ibid.

${ }^{33}$ Ibid.

${ }^{34}$ Ibid.
} 
A second approach to teaching media literacy developed from the field of cultural studies. The cultural studies approach focuses on the forces that influence popular culture. Teachers expect students to become more critical consumers of popular culture when students question commercial and cultural constructs and constrain of television. The goal for students is to learn how to resist what teachers regard as harmful commercial and cultural messages which saturate television. Teachers say they must "crack open" student resistance to their pedagogy in order to "equip students with the skills necessary to become active agents who question rampant consumerism as a social ideal and who recognize how the media attempts to manipulate its target audience". A similar pedagogy, directed at analyzing issues such as "diversity, racism, and sexism" on television programs is designed to "jolt our students out of their customary viewing habits and help them develop a reflective attitude" toward television. ${ }^{35}$

Again, there is much to be said for such an approach to the study of media literacy. No one would reject the value in having students develop a more critical understanding of why television is constructed and offered in particular ways. Knowledge is power, and anyone who has more knowledge about the values and assumptions that shape forms of communication can use that form of communication more attentively and carefully and with more attention paid to whether it is being used toward ends that will help society as a whole. The best examples of a cultural studies framework engage students in this form of inquiry effectively. These pedagogical approaches help students to reflect on how television texts are constructed and on how that shapes connections with such texts and the culture in which they are read. When done successfully, cultural studies pedagogy can provide students with a powerful set of analytical skills that allows

${ }^{35}$ Ibid. 
them to engage in and interpret popular cultural texts in a more elegant and thoughtful manner. The cost of not addressing in the classroom the cultural and political forces that shape popular culture texts is to leave such texts available for students without any form of analysis or critical reflection. ${ }^{36}$

An important goal is to view the way students watch television in order to become critical viewers. Teachers have the responsibility of improving the critical thinking skills in students as some times children need to be guided in the right direction as at times they may not have the capacity to develop their own concept of messages coming from mass media. The school curriculum presented should be improved to permit students to take pleasure from media. At the same time change the way they watch TV and interpret the messages from other media. ${ }^{37}$

The final approach is one between media. This perspective is a divide between popular culture, which is often regarded as lacking value, and print literacy, with is more readily accepted cultural capital. In examples of this pedagogy, Hobbs used "The Simpsons" as a means of introducing students to the work of Mark Twain and Joseph Conrad. In similar work on film, they found, "ways to assist students practice using analytical skills in considering films and then applying those skills to their job with literature."38

A positive aspect of this approach is the recognition that students' experiences with electronic media have provided them with knowledge that can be used in the classroom. Students move from their established knowledge toward more sophisticated

\footnotetext{
${ }^{36}$ Ibid.

${ }^{37}$ Ibid.

${ }^{38}$ Ibid.
} 
forms of print literacy, the most important aspect in the realms of education. Students gain some authority over at least part of the subject matter rather than simply being impressionable dupes. But, unlike the other approaches, there is a clear hierarchy between classroom print literacy and popular culture. As a result, television texts are regarded as raw and unsophisticated, further study of them or popular culture that produced them is for that reason pointless. They are, instead seen as means to the greater end of institutionally acceptable print literacy. Although other scholars have questioned this approach in dealing with elementary school students, it remains relatively unfamiliar in studies about middle school literacy pedagogy. ${ }^{39}$

A second problem with this approach is the connection between popular electronic media and print literacy. It is important to argue that there are multiple gaps between students' experiences with popular culture which is in turn is influenced by issues of culture, race, gender and class. Rather than applying the conventional where one simply goes around these gaps, educators must realize that there are multiple ways available for students and for their teachers to enrich themselves by studying experiences of one- another as such paths never offer a one-way trip. ${ }^{40}$

The English Language Arts Standards of California Department of Education Framework explains that the function of media literacy in education is to facilitate students to identify, analyze and critique persuasive techniques in media messages and analyze media as sources of information, entertainment, persuasion and transmission of culture.” Also students are required to trace growth and effects of radio and movies and

\footnotetext{
${ }^{39}$ Ibid.

${ }^{40}$ Ibid.
} 
their role in the worldwide diffusion of culture and to evaluate, take and defend positions on the influence of mass media on American political life. ${ }^{41}$

Many schools through out the United States have the objective of preparing students to investigate the source of media representation or production, such as who made it and why it was made. Also, it is essential for students to recognize genres such as nightly news, documentaries and new magazines, and identify the unique properties of each. In addition, it is important that a student examine the effect of media on the construction of the perception of reality and be conscious of how visual, sound techniques or design messages such as special effects, editing, camera angles, reaction shots, sequencing, and music are shown on television. ${ }^{42}$

Literacy and technology has always been connected. New technologies disclose new ideas of what constitutes literacy. Media literacy has the goal of figuring out how information is presented and what techniques should be used to manipulate the response of people. In addition, media literacy is not just about becoming smarter users of the technologies such as the Internet and educational software, it also about becoming innovative and flexible media creators. The idea of linking literacy and technology is made technology more likeable to the students. ${ }^{43}$

In the field of educational technology, teachers need to consider issues of student cognition, influence, and pedagogy. As this point it is crucial to study the relationship between the computer and the learner. The incorporation of educational software serves

\footnotetext{
${ }^{41}$ Considine, “Media Literacy: National developments and International Origins.”15.

${ }^{42}$ Louanne Ione Smolin "Becoming literate in the technological age: New responsibilities and tools for teachers" Journal of Reading Teacher (March 2003): 570.

${ }^{43}$ Punyashloke Mishra, Michael D. Nicholson and Steven K. Wojcikiewicz, "Seeing ourselves in the computer: How we relate to technologies” Journal of Adolescent \& Adult Literacy (April 2001): 5-7.
} 
as a tool in cognitive aspects of working with computers and a factor in the psychological and social aspects. ${ }^{44}$ Multimedia technologies like CD-ROMs and websites create fresh material for increasing education. The multimedia dimension in computers helps the students to experience sights, sounds and images of history as well as to learn essential details. ${ }^{45}$

The proper use of technology can give students enough knowledge to take advantage of technological media. The Internet possesses so much information that students should learn to manage it with the teachers. Students can take the best information presented on the Internet and software and learn to process and analysis the information. This is one of the reasons of why media literacy is taught on school, to achieve this idea. ${ }^{46}$

In addition to the above, media has always had an influence on determining the way politics has been conducted. For a long time, candidates for political office have relied on coverage of their campaigns in magazines and newspapers in order to get their messages across. They have bought ads in these media with the purpose of creating an image of themselves for the electorate. ${ }^{47}$

In the 1950s, television made a revolution as the new media and politics began to change considerably. Since that moment, there has been a gradual and continual erosion of the amount of influence the political parties’ possess. No longer do people have to be affiliated to political parties and go to their functions in order to feel informed and

\footnotetext{
${ }^{44}$ Ibid.

${ }^{45}$ Rhonda Hammer and Douglas Kellner, “Multimedia Pedagogy and Multicultural Education for the New Millennium,” Journal of Religious Education (Fall 2000): 5-8.

${ }^{46}$ Ibid.

${ }^{47}$ Danny Schechter, “The Challenge Ahead,” Journal of Politics (February 2001): 1-2.
} 
involved. Now main elections are much more important, and the party’s nominating conventions are much less important. But the biggest change is in the cost of campaigning because it is essential to use television and television is very exclusive as well as expensive. $^{48}$

Media is still used for the idea of winning elections. Politicians use mass media to govern. Politicians, through their exposure to the news confront the consequence of an exigent society that is not accepting of all the messages that they created to manipulate the audience. Politicians want to build an image of power and success using mainly newspapers and television. ${ }^{49}$

In the United States, politicians are accustomed to seeing the people as an instrument of the media, because society through the years has been educated and manipulated by media. Politicians persuade the society using techniques of political marketing, making strategies to catch the audience with an idea of something that is associated with their feelings and desires. ${ }^{50}$ Media sarcasm, that is cynicism and irony used in the messages, encourages public lack of interest, and this lack of interest means fewer voters. Projects at Harvard University point to the declining level of voting as a function of the loss of engagement by individuals in all phases of the political process. If true, this decline can be blamed in a considerable part to the media. ${ }^{51}$

If the media has become a type of danger to democracy, what are we going to do about it? Many people are convinced that the media's power will grow excessively in the

\footnotetext{
${ }^{48}$ James Potter, Media Literacy, Second ed., (London: Sage, 2001): 319-324.

${ }^{49}$ Ronald Berkman and Laura Kitch, “Politics in the Media Age,” (New York: McGraw-Hill, 1986): 322-323.

50 Ibid.

${ }^{51}$ Steve Bells, “The Media and Politics: It’s more than the News,” USA Today Magazine 9March 2001): 10.
} 
next years, unless and until progressive resistances appear, in the form of educated people. $^{52}$

Changes in the media had a direct impact on the nature of twentieth-century politics. The appearance of television, in particular, obligated politicians to think more about their public representation. It encouraged a focus on the rival party leaders, which reminded many people of American presidential contests. As the extended reporting of parliamentary proceedings disappeared from the pages of newspapers, and it became necessary to make a positive impression on the television news bulletins, the short, memorable utterance or sound bite assumed growing importance. By the 1980s, election campaigns were increasingly conceived in terms of their visual impact on the voters. ${ }^{53}$

The interpretation of manipulation of propaganda in the United States is a serious topic to talk about when we want to associate this to media literacy. Sometimes real stories are the things that politicians do not want journalists to write. At first these stories are denied and denigrated. ${ }^{54}$ One of the most important cases about personal and governmental life was the scandal between Monica Lewinsky and then President Bill Clinton. The mass media tried to link Clinton's personal life with his political work in the government. The coverage of the scandal did not have an influence on the popularity of the president. The public response of this scandal was not related to Clinton’s performance as a president at that time. ${ }^{55}$ When talking about political campaigns, mass media tends to be biased. Scholar Jonah Goldberg explain that "the citizens of this nation

\footnotetext{
${ }^{52}$ Lewis Lapham, “Notebook,” Harper’s Magazine (October 2002): 8.

${ }^{53}$ Graham Goodlad, “The media and British Politics in the Twentieth Century,” Journal of Mass Media and Politics (September 2003): 6.

${ }^{54}$ Paul Routledge, “The truth about political journalists,” National Review (July 2003): 14.

${ }^{55}$ Regina G. Lawrence, "Rethinking Media Politics and Public Opinion: Reactions to the Clinton-Lewinsky Scandal,” Political Science Quarterly (Fall 2001): 1-3.
} 
were enough media critical to understand how television, newspapers, magazines and Internet tried to impeach Clinton and how the nation was able to separate both events and be objective between the political and personal issues present in a politician. It is important to understand how the audience become critical thinkers and understand the difference between relevant information and manipulation of information.”56

The interpretation of politics in media can be highly criticized with regard to administration of President Bush. Being honest, objective and fair-minded reporters of the Bush Administrative policies requires reporting without bias the events and the conduct of the people of George Bush’s administration. There are segments of the media that accuse just about all the men and women responsible for the running of this nation's foreign (and many of its domestic) affairs of being entirely without personal honor when it comes to the affairs of state. This simply is not done in respectable journalism. It is time that citizens really analyze what President Bush has been doing and judge the merit of his actions based on objective journalism. ${ }^{57}$

How can the citizens of the nation be aware of the good and bad things present on the media about politics? The following is the importance of making media literate citizens: People are able to construct messages from mass media and learn to identify both sides of the story. For example in the case of the war between Iraq and the United States, citizens of the United States need more time to see the plight of the Iraqi people. Unfortunately, mass media in the United States just shows the good actions of American soldiers. This disrupts the natural opinion making process of Americans. They do not

\footnotetext{
56 Jonah Goldberg, “The Bankrupt State,” National Review (September 2000): 47.

${ }^{57}$ Eric Alterman, “Collin Powell and the Power of Audacity,” Journalism United States, Politics and Government (September 2003): 1-2.
} 
take time to show how many people die in Iraq and the situation there. This can be seen in television shows, newspapers, magazines, and on the Internet. The main reason behind the war was to find nuclear weapons, but they were never found, Bush the tried to persuade society by telling them that the war was necessary to put down a terrorist leader and create a new economy in Iraq, the falsified reasons behind going to war are never discussed. ${ }^{58}$ In American presidential campaigns covered by mass media, it is difficult to differentiate between real and unreal events. Real time images have been clearly manipulated by the media. Media literate citizens can create a new conception of politics when they learn the difference between good and bad political actions and the way media portray this. $^{59}$

Besides political issues Media literacy can use analysis of political advertising from the campaign process. Also, students can identify the techniques use to catch people attention and persuade their emotions and behavior. How media uses specific phrases and slogans. Each medium has a different way to cover political issues. Students and public should discover how television uses techniques to associate images and words that create powerful and persuading images. Newspapers are considered one of the oldest and respectable mass media and the challenge of teachers is to make their students aware of the differences between sources of news and how Journalists maintain biased points of view. The key of media literacy on politics is to realize what role media plays in the construction of messages and opinions to create in society a perception of politics and politicians. $^{60}$

\footnotetext{
${ }^{58}$ Richard Wolffe, “Bush’s News War,” Newsweek (October 2003): 1-2.

${ }^{59}$ Lewis Marker, “Fighting Reality Securities,” Data Publishing On Wall Street (July 2003): 3.

${ }^{60}$ Renne Hobbs, “Building Citizens Skills through Media Literacy Education”, Journal of the Center of Media Literacy (September 1998): 56-57.
} 
Psychology is also an important part in analyzing media literacy because making an individual understand how people learn to form stereotypes is a very important point of mass media and literature. ${ }^{61}$ Television is one of the most persuasive and powerful mass media. American television shows that people can achieve happiness if their have nice cars, and they are beautiful, young and vigorous. People are concerned about their beauty, the way they must dress, talk and behave from what they see through the mass media. Television shows, advertising campaigns, magazines, newspapers, cable and Internet give us the idea that perfect bodies and money is the central focus of people’s lives. How can kids grow up and have more sense of the importance of family, education and health and not to be so obsessed with the superficial aspects life? It is crucial to make society understand that not all the things that media show are good to learn. This is the reason media literacy is incorporated in the people's lives. It is necessary to make the distinction between the good, the bad, and persuasive of media messages. ${ }^{62}$

Television is an entertainment medium that can be used as a pedagogical tool to analyze the intersections of race, gender, and class subordination and challenge deficit discourse and raise social consciousness. ${ }^{63}$

In a study by the University of California, in Santa Barbara, two scholars emphasized how racism, gender and low profile Latin people are portrayed in the media. For example the media portrays Columbians to be drug-traffickers and Mexicans to be a race of illegal immigrants; this of course is not true. This study

\footnotetext{
${ }^{61}$ Gary Bowden, "Science, Society and the Human Genome Project (Film)," Canadian Journal of Sociology (Spring 1997): 2-4.

${ }^{62}$ Robert J. Samuelson “Adventure in Agelessness” Newsweek Article (November 2003): 2-9.

${ }^{63}$ Gloia Goodale, “What is missing from this picture?” Journal of Television (August 1999): 1.
} 
developed the critical race theory in which racism, sexism, and classicism are used in entertainment media. Additionally, it helped students to critically read on how Columbians and Mexicans are portrayed on the screen and develop critical media literacy. How can this image be changed? It is very important to show to society movies and books in which Columbians and Mexicans are shows as people who study and make big achievements in their lives. ${ }^{64}$ The utilization of media as a pedagogical instrument in the effort to raise social awareness and work towards social justice is the basis for the change of the image of Columbians and Mexicans in American society.

Another study about race in mass media is reflected in the images that Americans have about Italians. Most of the roles that these people play on the screen are as a criminals and "pasta eating buffoons". ${ }^{65}$ On the other hand, the representation of Arabs in the United States electronic media is another case of racism in media. Studies of mass communication explain that Arabs are associated with violence and terrorism. Arabs through the years have been portrayed as aggressors more than peaceful people. Wars and global conflicts shown on the news make Arabs in people's mind powerful and dangerous. ${ }^{66}$

On the other hand, television shows give the impression that the use of foul language, violence and sex of television constitute something nice and fashionable. Prime time shows like reality programs portray all the characteristics mention above. ${ }^{67}$ The scenes of sex out of marriage are shown ten times more that inside of marriage in

\footnotetext{
${ }^{64}$ Tara Yosso, “Critical Race Media Literacy: Challenging Deficit Discourse about Chicanas and Chicanos,” Journal of Popular Film and Television (Spring 2002): 3-10.

${ }^{65}$ Yahya R. Kamalipour and Theresa Carilli, Cultural Diversity and the U.S Media (New York, State University of New York Press, 1998): 111-116.

${ }^{66}$ Ibid., 157-167.

${ }^{67}$ Lewis Grossberger, “The Curse of the Curse,” Media Week (September 2003): 34.
} 
television shows. In addition, scenes of violence like cars exploding are the characteristic of action movies in America. Talk shows and soap operas make divorce and adultery appear as normal issues happening in society. ${ }^{68}$ Violent programs can have an enormous impact on people's attitudes and behavior of teenagers and adults. ${ }^{69}$ However, other bad habits like smoking are highly imitated by kids and teenagers. Smokers in movies increase the chances of a young person picking up smoking three fold. ${ }^{70}$ Millions of people who watch television programs and movies listen and have opinions concerning media. Media should promote the values of the community like education, religion and family. For example, television should promote more channels like Discovery Channel and A\&E that produce programs that showcase issues about education, religion and family around the world. ${ }^{71}$

The idea of developing media literacy is fundamental to making students understand the messages that mass media shows. The study and analysis of the relation between media and literacy helps students and people in general to become critical thinkers, in other words, to understand the good and bad messages from the media, to figure out why the messages are presented in the way they are and how everybody can take advantage of this and apply on their knowledge. ${ }^{72}$ Being able to deconstruct and

\footnotetext{
${ }^{68}$ Michael Medved, “That is Entertainment?” National Interest (Summer 2002): 5.

${ }^{69}$ Jonathan L. Freedman, Media Violence and Its Effect on Aggression (Toronto: University of Toronto Press, 2002), 208-210.

${ }^{70}$ Stanton Glantz, “Smoking in movies: a major problem and a real solution,” Lancet (July 2003): 2.

${ }^{71}$ Roger Mahomy, “God and Hollywood,” New Perspectives Quarterly (Spring 1995): 4.

72 Erica Scharrer "Making a case for media literacy in the curriculum: Outcomes and assessment” Journal of Adolescent and Adult \& Adult Literacy (December 2002): 354.
} 
analyze media messages for content exactness and intent represent important skills that are crucial to making media literacy work. ${ }^{73}$

The success of media literacy in education, technology, politics and sociology began with those educators and scholars who designed and implemented the teaching of education in media literacy. The opportunity of sharing experiences and strategies that exists between teacher and student can create a new concept of media message perception. This is achieved through media activities that teachers develop in class for their students. $^{74}$

The study of media literacy inside the classroom opens a new window to students and teachers. The attitude, opinions and thoughts of the students are crucial in the study of the media and how this helps to reduce the negative behavioral effect of media. Also, the cognitive sense that students develop during their analysis and interpretation of messages plays a role in increasing the awareness of people about advertising, violent scenes on TV and racial discrimination. ${ }^{75}$

Media literacy provides the opportunity to analysis from different perspectives social, economy, political and cultural issues that surround human beings, including messages, information and knowledge. Due to media literacy students are able to construct and analysis their own messages by creating their own television shows, web pages, advertisements, newspaper, and magazines articles. This places students in a position to be givers and receivers of information, this enables them to better understand

\footnotetext{
${ }^{73}$ Susan Hill and Gordon B. Lindsay, “Using Health Infomercials to Develop Media Literacy Skills,” Journal of School Health (August 2003):2.

${ }^{74}$ Renee Hobbs, “The Seven Great Debates in the Media Literacy Movement,” Journal of Communication (Winter 1998): 5-9.

${ }^{75}$ Gary R. Edgerton and Michael T Marsden, "Media Literacy and Education: The Teacher Scholar in Film and Television,” Journal of Popular Film and Television (Spring 2002): 1-5.
} 
what is going on around them and understand more about mass media context. Schools and universities must include media literacy as a part of their curriculum to construct a more cultural society. ${ }^{76}$

Apart from a formal system of education that prepares people to be more critical thinkers it is of interest to observe how communication through the media began to be effective in people’s lives. The media literacy process is analogous to many social scenarios. For instance since the Industrial Revolution, society has changed with the implementation of new machines, companies and products that changed people's lives. In the 1930s and 1940s, populations began to move from farms to cities and mass media came of age as it was now a fundamental part of life. At this time technological communication emerged as a new way of diffusing information. The diffusion and adaptation of media in peoples' life is similar to the diffusion and adaptation of other tangible things. To further understand how the above ties into media literacy we take the help of the Diffusion Innovation Theory.

Diffusion theory is a process to understand how ideas, products, and opinions are disseminated through a society, and to analyze how fast or slow it occurs. One of the most important studies of innovation process was carried by Ryan and Gross in $1943 .^{77}$ Their study about the diffusion of a hybrid seed corn, more than any other study, influenced the methods and interpretations of later studies in the field of sociology. A total of 259 farmers were interviewed in two small Iowa communities, Grand Junction and Scranton. The hybrid seed implementation did not continue in the second generation of people; farmers had to purchase hybrid seed annually, whereas previously they

\footnotetext{
${ }^{76}$ Arli Quesada, “The Media Literacy Imperative,” Technology and Learning (October 2000), 1-5.

${ }^{77}$ Rogers and Shoemaker, Communication of Innovations, Second Ed., (New York: the free press, 1971): 54-55.
} 
selected their own-pollinated seed. The major advantage of the innovation was a $20 \%$ increase in the corn, because of the incorporation of mass media and the use of interpersonal channels to influence people about the new product. Hybrid seed corn appeared in 1928, and was almost completely adopted by $1941 .^{78}$ The big difference between the first and the last adaptation at that time shows that structural and sociopsychological factors such as age; social status and education influence the diffusion of innovations.

When the hybrid seed corn was implemented in the market just a few farmers bought the new corn. Over the years more and more farmers adopted this new corn until some point, within years all farmers have adopted the hybrid corn. This was the adoption s-shaped curved, that began slowly but hastened where all members of a system adopt the innovation. ${ }^{79}$

The above-mentioned study is based on hybrid corn seed, a tangible thing yet the diffusion and process of acceptance of these hybrid corn seeds is similar to how society accepts media into their life. Rogers hypothesized that there are four factors that influence adoption of an innovation. These include 1) the innovation itself, 2) the communication channels used to spread information about the innovation, 3) time, and 4) members of a social system. ${ }^{80}$ However certain catalyst aids these factors and the extent of diffusion of the innovation is also dependant on personal traits of those adopting the innovation. Rogers said that there are four major aspects that deal with the diffusion of innovations:

\footnotetext{
${ }^{78}$ Ibid.

${ }^{79}$ Thomas Valente, Network models of the Diffusion of Innovation, (Cresskill, New Jersey, The Hampton Press communication series, 1995), 2-4.

${ }^{80}$ Rogers and Shoemaker, Communication of Innovations, 18.
} 
1) Knowledge: The individual is exposed to the innovation's existence and gains some understanding of how it functions.

2) Persuasion: The individual forms a favorable or unfavorable attitude toward the innovation.

3) Decision: the individual engages in activities that lead to a choice to adopt or reject the innovation.

4) Confirmation: the individual seeks reinforcement for the decision made, but he may reserve his previous decision if exposed to conflicting messages about the innovation. $^{81}$

These aspects can be seen all around us, understanding how these theories are implemented and used by the mass media can be learnt by the proper use of media literacy pedagogies. Media literate people can understand and identify the diffusion process as the media makes deliberate use of it. Rogers also mentioned that there are five categories of innovation adopters as described in The Individual Innovativeness Theory.

These five categories of adopters are:

1) Innovators: Venturesome

The innovators are eager to try new ideas. Their interest leads them from a local circle of peers and into more cosmopolitan social relationships. Communication patterns and friendships among a clique of innovators are common, even though the geographical distance between them may be great. The valiant value of the innovator is venturesomeness. He desires the hazardous, the rash, the daring and the risky.

2) Early adopters: Respectable

Early adopters are a more integrated part of the local social system than are innovators. Where innovators are cosmopolites, early adopters are localites. This adopter category, more than any other, has the greatest degree of opinion leadership in most social system. The early adopter is considered by many as "the man to check with” before using a new idea.

3) Early majority: Deliberate

The early majority adopts new ideas slightly before the average member of a social system. The early majority interacts frequently with their peers, but rarely hold

${ }^{81}$ Ibid., 125-127. 
leadership positions. The early majority may deliberate for some time before completely adopting a new idea.

4) Late majority: Skeptical

The late majority adopts new ideas just after the average member of a social system. Adoption may be both an economic necessity and the answer to increasing social pressures. They can be persuaded of the utility of new ideas, but the pressure of peers is necessary to motivate adoption.

\section{5) Laggards: Traditional}

Laggards are the last to adopt an innovation. They have few leadership skills. They are local in their outlook of all adopter's categories; many are near isolates. Laggards tend to be frankly suspicious of innovations, innovators and change agents. While most individuals in a social system are looking to change ahead, the laggard has his attention fixed on the rear-view mirror. ${ }^{82}$

Apart from personal traits as described above and the sophistication level of media education there are factors that influence the adaptation of new things including media. The merits or the perceived merits of the new innovation play a role in how society responds to the innovation. The theory of perceived attributes claims that a new product can be adopted if the people perceive it with good attributes, in other words, if people see that the products have benefits and help then in their purpose they will use it. To achieve this, at first the innovation needs to have some advantages, second it needs to be compatible with real practices and values. Third, the new product can be too complicated for society and the last one; the innovations must have triability, which the innovation should be probe to get results that people can see.

Media has evolved tremendously in the last century, especially with the creation of the Internet. If we treat mass media as a commodity and understand that the inclusion of it in society is not much different to that of other commodities, we can

\footnotetext{
${ }^{82}$ Ibid., 185.
} 
use studies and theories developed for other things and apply them to media. Other factors that have played a role in the rise of mass media as an innovation through the years and still do are concepts like the Rate of adoption.

Rate of adoption is the relative speed with which members of a social system adopt an innovation. The rate of adoption claims that adoption is presented in a kind of Sshape curve. In the study of the hybrid seed corn, the innovation process was adopted in different categories and times. Farmers did not want to think about new technologies. But the depression in the 1930s and other random unfortunate circumstances in some farms were some of the factors that obligated farmers to implement seed corn in their field. The time of adoption depended on the characteristics of the farmers and their ability to take new risk. At the beginning, some farmers just tried seed corn in a part of the plantation that they have in the farms. Others used in all fields of the plantation to get quickly results; and few farmers rejected to use the corn until some years later, they saw the result on their neighbor's farms. Farmers just wanted to see results in other farms and take the risk. This is the reason the innovation began slowly but then, gained momentum and years later, many people adopted this product in their fields. ${ }^{83}$

The degree of communication in a society is fundamental for the adoption of an innovation. The stage of awareness and knowledge between people in a community permits the new product to take a new direction in society. The degree of influence of interpersonal channels was fundamental to helping people adapting to new products and understanding their advantages and disadvantages of it. Communication between farmers

\footnotetext{
${ }^{83}$ Shearon A. Lowery and Melvin L. DeFleur, Milestone in Mass Communication Research, Third Ed., (N.Y: Longman, 1995), 127-131.
} 
and neighbors in the rural area improved the rate of knowledge and rejection or adoption of the product. ${ }^{84}$

The diffusion of a new innovation into society is mostly a positive thing. But in some situations there can be factors that make the acceptance of new innovations an issue. We need to be aware of the other side of the situation to be better informed and more educated. Over adoption is one of the dangers; over adoption is the adoption of an innovation by an individual when experts feel he should reject it. Over adoption may occur, first because of insufficient knowledge about the innovation on the part of the adopter, second, inability to predict its consequences and third, enthusiasm for all that is new. $^{85}$

In a study conducted by Tucker in 1961, it is claimed that farmers of different counties can have the same perceiving characteristics, in other words, farmers from Alabama and Texas can have the same perception about the risk of implementation of new products. This study gives tells us that the same will be true in the case of mass media and the pattern of becoming media literate must be the same and therefore we can apply the same media education approach over the wider spectrum. Kivlin in 1960 showed that adopters have different perceptions and these are related with each person's circumstance and at the same time these perceptions affect the way people perceive the new product. For example a laggard and an innovator differ in time and manner each adopted the process of implementation of a new product. ${ }^{86}$

\footnotetext{
${ }^{84}$ Ibid.

${ }^{85}$ Roger and Shoemaker, Communication of Innovation, 167-168.

${ }^{86}$ Ibid., 138.
} 
Before concluding the discussion on the innovation-decision process, it is important to consider the consequences or changes that occur to an individual or to a social system as a result of the adoption or rejection of an innovation. Rogers identifies two consequences or changes.

There are functional and dysfunctional consequences. Functional consequences are desirable effects of an innovation in a social system. On the other hand dysfunctional consequences are undesirable effects in society. Consequences are changes that are recognized by society and when these are latent consequences it means that they are not tried and recognized by the general public. ${ }^{87}$

The theory of diffusion of innovations has been very important over the years, because it proved the importance of a communication process at the moment of a product is introduced. In a time when radio was greatly accepted, the newspaper was highly respected and magazines complemented newspapers even with mass media influence on the people, interpersonal communication channels were more influential for the farmers reaching a decision. Also, their social, economical and educational conditions were very important in the adoption of the hybrid seed corn. The theory of diffusion has been a crucial component in the diffusion of communication to the masses in the two-step model, which is discussed later on.

During the second presidential campaign of Franklin Roosevelt when the theorists wanted to prove how people choose one candidate (Democrat) over another (Republican). Paul F. Lazarfeld, Bernat Berelson, and Hazel Gaudet conducted a research project called The People’s Choice: “How the voters make their mind in a presidential campaign.”

\footnotetext{
${ }^{87}$ Ibid, 331-333.
} 
Here they are seeking to understand the way people vote in a presidential campaign and what or who part of that influence was. ${ }^{88}$

In this study questions were designed to be answered by a group of people carefully selected. The participants of the study were asked questions about their preference first at the beginning of the study, then during, and the end of the campaign. The study did not show any change in the way people decide to vote. ${ }^{89}$

The people who considered themselves Republicans or Democrats affiliated themselves with these political parties based on their background of religious, economic and social aspects. For example, Democrats were usually people of the labor class and Republicans are usually people from a higher class. Nevertheless, propaganda plays a role of persuasion in the mind of the society. Also, the use of activation and persuasion were important in the struggle of catching the attention of public. The use of radio was important because it touched the feeling of Americans. At the time of great depression, radio was in a boom and people liked to listen to the voice of the President and feel his speech. Still people did not realize that they were being persuaded by the mass media. However in the case of interpersonal relations things were different from what scholars expected from this study. They found that at the last moment people could change or keep decisions for many reasons. The first was family pressure; if a father was Republican or Democrat he wished his family to show the same political pattern. In addition, if there was not a strong belief in the President and his proposals, people could switch at any moment. In discussions with friends and neighbors, persuasion was present

\footnotetext{
${ }^{88}$ Paul Lazarfeld, Bernard Berelson, and Hauzet Gaudet, The people choice: How the voters Makes Up His Mind in a Presidential Election, (New York: Columbia University Press, 1948), 20.

${ }^{89}$ Ibid.
} 
and had an effect in the knowledge and actions of each person. There was no conscious awareness about the existence of manipulation in this interpersonal conversation. Towards the end this had more effect on the decision of the voters than mass media. ${ }^{90}$

Lazarfeld, Berelson and Gaudet first introduced the two-step flow of communication, focused on the presidential campaign of Franklin Roosevelt. The purpose of this study was to find experimental information about decision making by society. ${ }^{91}$ At this time they found more information about the influence of interpersonal channels and mass media on voting decisions. Decisions were communicated from newspapers and radio through opinion leaders and then to the less active parts of the population. ${ }^{92}$ The two-step flow of communication maintained the flow of information from sources to opinion leaders and then from leaders to their followers, both involved in the spread of information.

The study of the two-step flow was not well planned, because the researchers did not take the interpersonal communication seriously and they did not anticipate the importance of it. Receiving and sending information was a strong point in the diffusion process of ideas. $^{93}$

Two major criticisms of the two-step hypothesis need to be mentioned at this point. Firstly, the media was used to making people aware of the existence of new ideas. Communication was fundamental in all diverse stages of the innovation process. There was a lack of connection between the ideas and the adoption process and there was little

\footnotetext{
${ }^{90}$ Lowery and DeFleur, Milestone in Mass Media Research, 90-91.

${ }^{91}$ Paul Lazarfeld, Bernard Berelson and Hazel Gaudet, the People Choice, Second Ed., (New York: Columbia University Press, 1948), 151-152.

${ }^{92}$ Http: www.uky.edu/ drlane/capstone/mass/diffusion.htm. Communication Capstone spring 2001 theory book, pg 1 , accessed on 10-14-03.

${ }^{93}$ Everett M. Rogers, Diffusion of Innovations, (New York, The Press of Glencoe, 1962), 211-214.
} 
knowledge of the influence of communication among people. Most individuals discussed the innovation with their friends, neighbors and relatives. At first mass media introduced the new idea, but then, the people exchanged ideas in order to take decisions. ${ }^{94}$

The point of view of opinion leadership had a big variation in comparison with the analysis of the two-step flow in the original presidential campaign. Something that was not taken in consideration was the influence of the opinion leaders in their individual characteristics on establishing an opinion leadership. ${ }^{95}$

Lazarfeld and Katz developed some conclusions based on the investigation made of “The People’s Choice”:

First, they found responses to media messages were mediated through social relationships, the effects of media being limited by interpersonal relationships and group membership. They also found that those political campaigns could persuade the public and serve more dynamic and reinforced voter tendency to change attitudes. Katz and Lazarfeld argued that "interacting individuals seen collectively and continuously to generate and to maintain common ideas and behavioral patterns which they are reluctant to surrender or to modify unilaterally, in other words people were afraid of new changes."96

Hovland confirmed this theory of who identifies our adherence to group norms as a major factor. ${ }^{97}$ Hovland in his book "Communication and Persuasion” explains that the change in opinion induced by direct personal experience is though to be even more

\footnotetext{
94 Ibid.

95 Ibid.

${ }^{96}$ Elihu Katz and Paul F. Lazarfeld, Personal Influence: The Part Played by People in the Flow of Mass Communications, (New York: Free Press, 1965), 160-174.

${ }^{97}$ Ibid., 175-180.
} 
lasting than those produced by mass media, although systematic comparisons are available. $^{98}$

Second, it is misleading to think of "receivers" as a member of a "mass audience" since that implies that the people are all equal as receptors of media messages, whereas in fact some play a more active role than others. ${ }^{99}$ Opinion leader's exposure to magazines and radio is greater than that of non-opinion leaders. The interpretation of the message by mass media, specifically propaganda, is going to be more understandable to people who have a high exposure to the media and read magazines and books. Receiving a message does not imply responding to it; nor does non-reception imply non-response (since we may still receive the message via interpersonal communications). ${ }^{100}$

Lazarfeld and Berelson made an important point in this study. The most important thing about a study of communication is to investigate everyday processes, which influences people and makes them understand the relation between the everyday influence process and the mass media. ${ }^{101}$

In 1948, Harold Lasswell described the model of communication. This is based on a person who writes a message on a specific topic and sends it through a specific channel and with a specific effect. Some scientists believe this model to be the starting step in communication of ideas. The who in the message is studied to figure out the people and

\footnotetext{
${ }^{98}$ Carl I. Hovland, Irving L. Janis and Harold H. Kelley, Communication and Persuasion (London: Yale University Press, 1953), 243-245.

${ }^{99}$ Elihu Katz and Paul F. Lazarfeld, Personal Influence: the part played by people in the flow of mass communications, 175-180.

100 Ibid.

${ }^{101}$ Elihu Katz and Paul F. Lazarfeld, The Part Played by People in the Flow of Mass Communications, 160-174.
} 
organization that created the messages, the what gives society an idea of media context, to whom and with what effect permit an investigation of the audiences on mass media. ${ }^{102}$

A small number of people know about the model of communication of Shannon and Weaver, it is known that there exist a sender, a channel and a receiver. One of the problems with transmission model is that the source is the decision maker and the destination is passive. The sender chooses a message to send, and the receiver simply receives that message rather than be an active participator in the communication process. But communication is a two-way process, a complex system of signal passing back and forth between the participants. People talk to each other, there is never a one-sided conversation, and even if the other person is silent their body language and facial expressions may speak volumes. Transmission models suggest that communication is always intended, that the sender always sets out to send a message to the receiver, but communication can be unintentional. As it is pointed out before, people communicate by body language and by facial expression, often revealing far more about our thoughts than what we say. ${ }^{103}$

Katz and Lazarfeld suggested that Mass Media messages are planned and predictable, in contrast to interpersonal messages where context of the message can vary, depending of the conversation and the role of sender and receiver. In addition, in a faceto-face conversation, the relation in communication is closer than mass media and their audience, and the feedback created between two people in a conversation is fast and specific. Between mass media and people there is no specific feedback because the media is sending messages to the public and sometimes it is uncertain if the people are receiving

\footnotetext{
${ }^{102}$ Lawrence Grossberg, Ellen Wartella and D. Charles Whitney, Media Making: Mass Media in a Popular Culture, (London: SAGE Publications, Inc, 1998), 17.

${ }^{103}$ Denis McQuail, Mass Communication Theory: an introduction, (London, Sage Publications, 1994), 30.
} 
it. In interpersonal communications the receiver can adopt himself to the conversation as well as the sender, but with mass communication this direct connection of establishing opinions and change ideas in a short period of time does not exist. ${ }^{104}$

The communicating of innovations in the 1940s had one thing in common: the interpersonal messages were more important than messages that comes from the media, people's access to their neighbors and relatives was far more important than today where mass media represents a part of every day people's life. We are aware of the existence of products, services, and news because of the newspaper, radio, magazines and Internet. Also, people have less contact with their neighbors and relatives, but urban life allows people to relate with each other. Technology and media dominate the world of communication and the way people behave, dress and talk form part of media culture. In the past people began to move from farms to cities and they became consumers of a variety of products and services. This increased in a reasonable manner when mass media entered the market to introducing a new conception about what was and is the ideal society: new technology everyday, money, power and beauty.

\section{Hypotheses}

Hypothesis1: Media literate people, whose habits have been shaped for years by mass media, are more frequent media users than people who do not read, watch or use different kinds of mass media frequently (Television, Newspapers, Magazines, Radio and the Internet).

Hypothesis 2: People, who frequently watch, read or listen to sources of different mass media, at school become more critical thinkers in comparison with the people who do not read, listening or watch mass media frequently. 


\section{Methods}

A pilot study was conducted for this project to explore media literacy habits. People with higher levels of media literacy had better and more frequent use of mass media than those who showed a low level of exposure and selectivity to media. The methods used to show these results were to interview the people with open-ended questions. These questions were designed to learn about people’s behaviors and attitudes in relation to mass media. The results found in this study show that family constitutes the foundation of media habits. Also, from an early age when people begin to read the newspaper at home and watch the news with their parents, they become more critical thinkers. They began to form preferences and political inclinations (Republican or Democrat) from what they heard at home. The people who had not had family discussions about mass media show a lower level of media usage as they do not show a strong interest in specific magazines, newspaper or television shows. The results found that people have some idea on how to become media literate. They think that the frequent use of television, magazines, newspapers and radio helps people to differentiate between good and bad messages. Some people think that media can sometimes be biased not just in the United States but also in other parts of the world and that television channels broadcasting the news use stereotypes and narrowly focus on certain issues. Frequent media activities allow people to analyze and evaluate media messages and criticize the values and ideologies that they represent and improve people's assessment of the media messages.

A person's level of media literacy can be measured by the frequency use of mass media and the level of understanding people have when they analyze different media. In

104 Ibid. 
these interviews, 3 of the 5 people interviewed use mass media regularly. They are in the habit of reading magazines and newspapers regularly and understand the importance of shaping media habits and how it helps them become analytical thinkers and be more knowledgeable in many areas.

The interviews conducted for this research support in part the hypothesis formulated before: media literate people whose habits have been shaped for years by mass media are more aware of media messages than people whose habits have not been shaped by mass media. Most of the people interviewed say that they become more analytical thinkers from family habits and the frequent use of media like television, radio, newspapers magazines and the Internet.

An Institutional Review Board (IRB) approved survey was conducted to generalize and support these findings. The survey questionnaire with close-ended questions was applied to a population selected using a convenient sampling method. The questionnaire was applied to 350 students to understand their behaviors and attitudes in relation to their mass media background and habits, as well as questions about critical thinking.

\section{Results and Discussions}

Media literacy is defined as the way people analyze and interpret messages from mass media. The purpose of the survey used in this study was to analyze how people become media literate, their frequency of media use habits and critical thinking skills. It is important to know background information and what their likes and dislikes are about mass media. This survey explored people’s behaviors and attitudes in relation to mass media, how literate people are about mass media and their critical thinking skills. 
An analysis of the data from the survey verifies the hypotheses that the sooner a subject starts to develop his or her critical thinking skills the more critical a thinker he or she will be. It will be beneficial for parents to start the process of involving their children in discussions about events covered by media. It is important that content of the media upon which the young person's media education is based to be monitored by both parents and teachers. This is particularly important as young children have rudimentary skills and knowledge structures, and their analytical abilities are still in the development stage and a level of guidance by those with more seasoned knowledge structures will be beneficial to the young person. Based on the survey results it can be observed that those who stared their media education in elementary school but interrupt their media education sometime between elementary school and college were not as media literate as those who continued their media education through out the years. People who regularly used more than one source of media were more media literate than people who used only one media source. Additionally, the results make it clear that those who shaped their media habits over the years are more frequent users of media.

The sample population for this study was divided into three groups. The group definitions are as follows:

Group 1 consist of 166 people who are classified as strong media literate people who frequently and very frequently used at least 2 out of 5 media (television, newspapers, magazines, radio and the Internet). In addition to their classroom discussions they discussed media events with their parents and peers during their elementary school, high school and recent college years. These people started shaping their media habits in the early stages of their life (elementary school through college years). 
Group 2 consist of 53 people who are classified as moderate media literate people who frequently and very frequently used at least 2 out of 5 media (television, newspapers, magazines radio and the Internet). In addition to their classroom discussions they discussed media events with their parents and peers during their elementary school, high school and recent college in years. These people started shaping their media habits in the later stage of their life (high school through college years).

Group 3 consist of 49 people who are classified as low media literate people who according to the survey did not fall in the above groups. On an average they use one or no media. These people consist of the population that may have started their media education at an early stage but their media education may have been interrupted or discontinued or may even have been sporadic.

Hypothesis 1 states that among media literate people, those who have shaped their media habits over the years are more frequent media users nowadays as compared to those who have not shaped their media habits over the years

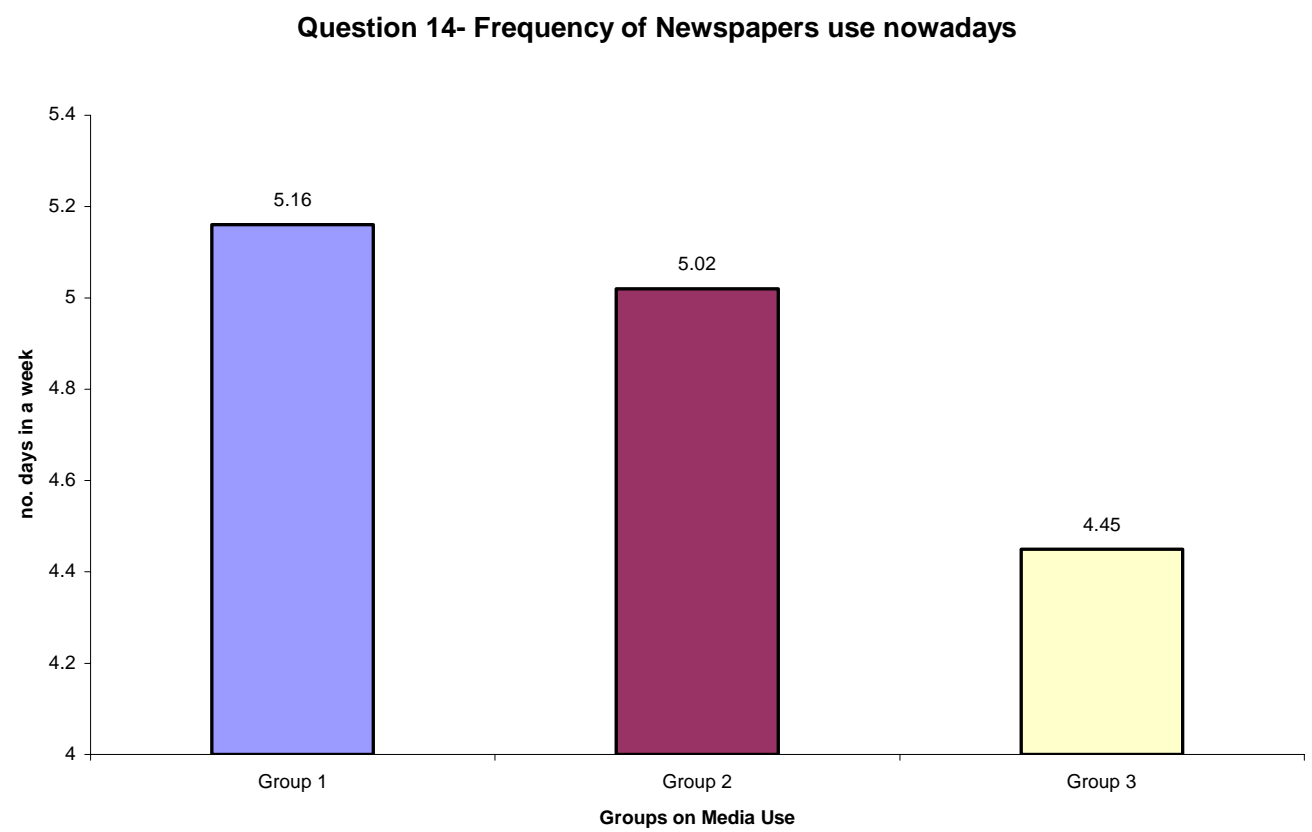


Question 15- Frequency of Television use nowadays

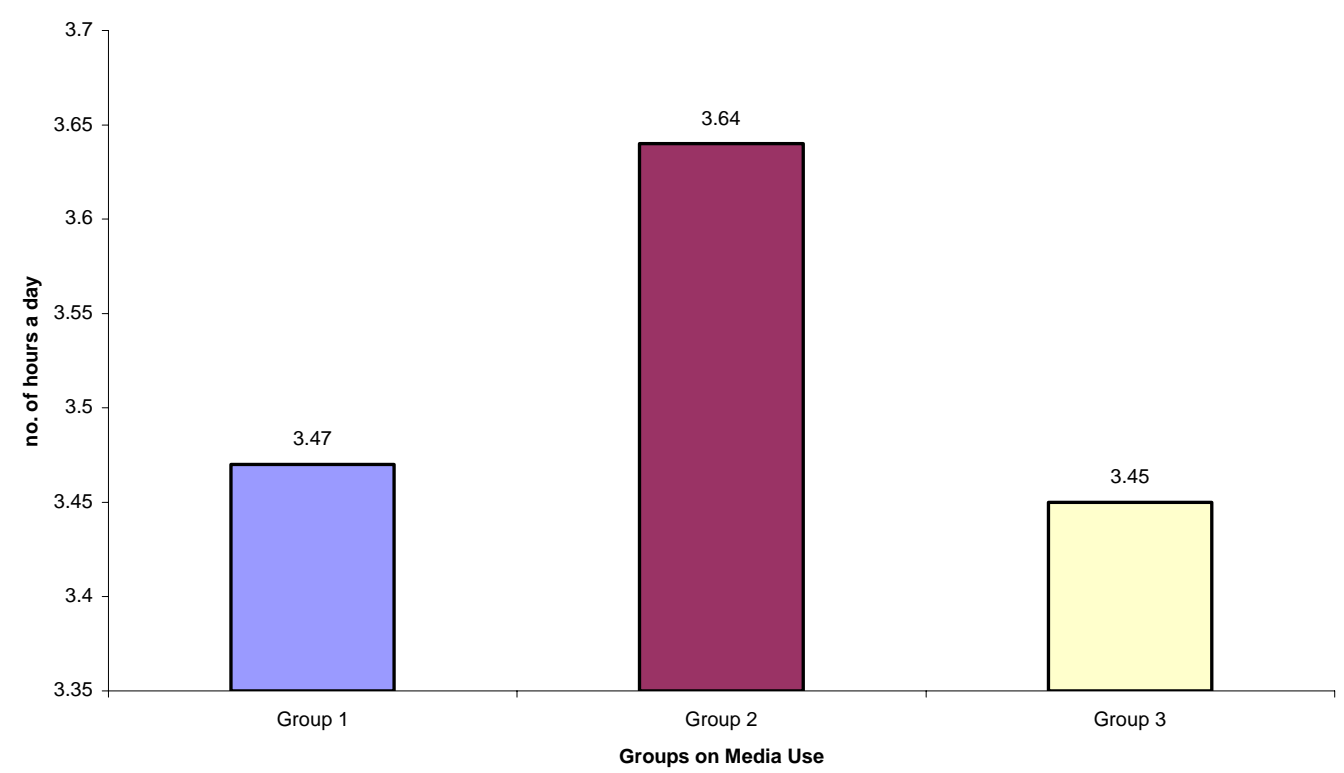

Question 16- Frequency of Internet use nowadays

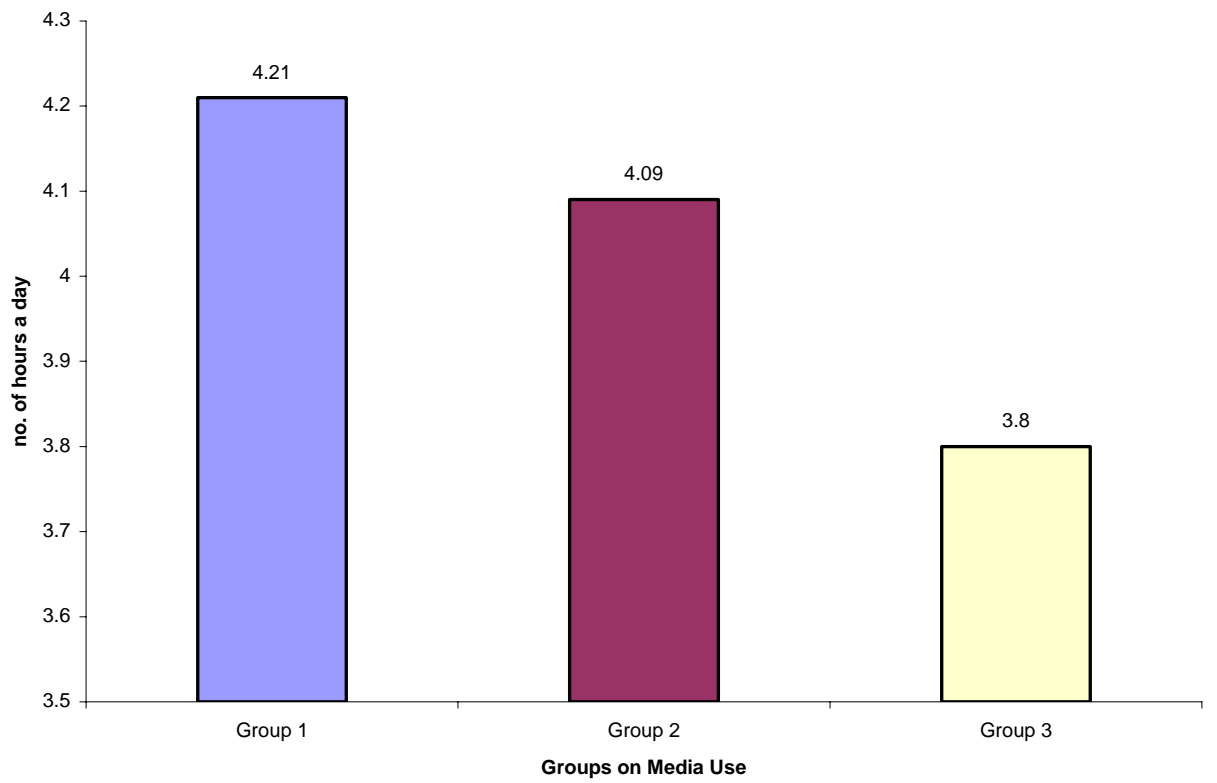

Group 1 पGroup 2 口Group 3 
The above hypothesis is supported by the result based on the data collected from the survey. The figures below do in fact show that members of group 1 (strong media literate people) are the most frequent users of media. Next are members of group 2 (moderate media literate) who started their media education process later than the people from group 1. People from group 3 (low media literate) were behind people from group 1 \& 2 in newspaper and internet use.

It may be concluded that members of group 1(strong media literate people) are more frequent users of media based on the results of the survey. In two of the three categories (Newspapers and Internet), members of group 1 proved to be more frequent users of media. From the data available it can be seen that Group 1 members watch an average of over 3 hours of television, read the newspaper 5 times a week and use the Internet for 4 hours. This is more than the media use of people from group 1 who read the newspaper less than 5 times a week and uses the Internet for under 4 hours a day. It is worth mentioning that television usage of group 1 and group 3 is almost the same. Group 2 (moderate media literate people) members are more frequent users of media as compared to members of group 3(low media literate people). They barely read the newspaper 5 times a week and surf the Internet for just over 4 hours a day. The people in group 2 were found to be the most frequent users of television, even if it was by a small margin. This trend is similar to group 3. This may be due to the fact that the television is a medium used more for entertainment rather than used for information gathering like the newspaper or Internet; therefore in this case it is the content of this medium that creates the difference. However, in keeping with the hypothesis we may still conclude that those who started their media education in elementary school and continued to be educated in media education throughout college are the most frequent users of media nowadays. 
People in group 3(low media literate) who on an average used only 1 out of 5 media, are frequent users of media, but not as much as those in group 1(strong media literate) and 2(moderate media literate). This can be attributed to the fact that this group (low media literate) consists of those who started their media education in elementary school and in high school, but on an average used only 1 source of media. In the case of group 2, the group that was made up of people who used 2 out of 5 media but started their media education only in high school, it can be seen that while they too were frequent users of media they cannot match the media use of group 1 .

Based on the above discussion we can conclude that the hypothesis that, among media literate people those who have shaped their media habits over the years are more frequent media users as compared to those who have not shaped their media habits over the years. This conclusion is based on the data that showing group 1 (strong media literate) to be consistently ahead of the other groups. Also to be mentioned is that there was almost no difference between the media use of males and females. We may conclude that gender has little to do with the frequency of media use and the only determining factor is how early the media education was started.

The survey included 5 questions to evaluate the critical thinking skill of the 3 groups. The results revealed a difference in the skills of the different groups. Hypothesis 2 states that amongst media literate people, those who have shaped their media habits over the years are more critical thinkers as compared to those who have not shaped their media habits over the years. 


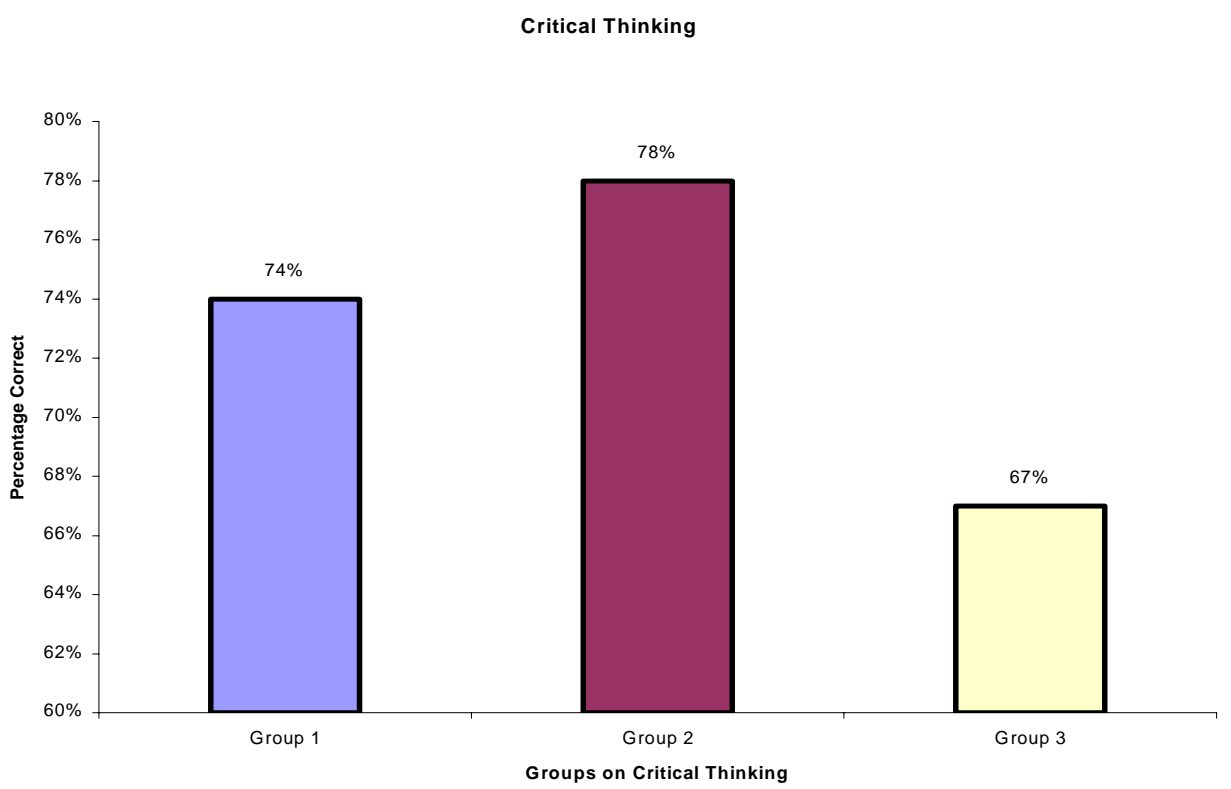

The data from the survey gives us the following information. Members of group 2 who are moderate media literate (78\% correct answers), people who began their media literacy habits in high school were more critical thinkers than people from group 1 who are strong media literate ( $74 \%$ correct answers), who started their media education in elementary school. Group 3 members who are low media literate (67\% correct answers), had the least number of correct answers from the critical thinking part of the survey.

It can be seen from the survey results that members of group 1 and 2 scored high on the critical thinking part of the survey. This shows that people in both group 1 and 2 are highly critical thinkers. People in group 2 did slightly better than the people in group 1. This may be explained by the concept of knowledge structures; the results also have a relation with the frequency of use of the number of media units. People who are strong and moderate media literate use 2 out of 5 media. On the other hand low media literate people only used 1 out of 5 media frequently. However, in relation with the knowledge structure topic the argument is that there is not a significant difference between group1 
and 2, strong and moderate media literate because people in group 1 who start shaping their media habits when they are children and children in elementary school years do not have very mature knowledge structures. Knowledge structures are events and experiences that a person uses to develop his or her understanding. Knowledge structures are based on rudimentary skills and developed skills. Children have only rudimentary skills because they are not mature enough to understand the differences between the real world and the media world. ${ }^{105}$ When a child starts his or her media education at a young age, not being able to differentiate between real world and the media world he or she can form knowledge structures that are misguided. So while it is important to start the media education at a young age the content of media education can make a difference and media education amongst young children must be monitored carefully. If people are educated in media literacy based on poorly formed knowledge structures they will not be as critical thinkers as they might have been had they based their media education on more mature knowledge structures.

The above explanation can be used to explain why group 2 performed better than group 1. At the same time this in part supports the hypothesis, as people in group 2 (moderate media literate) did perform much better than the people in group3 (low media literate). Group 3 consists of people who on an average were users of 1 out of 5 media. This group includes those who started their media education at different stages of their life but used only 1 source of media. Based on a comparison of results between group 2 and 3, we can conclude that media education stated sooner makes people more critical thinkers. It can also be said that people of group 2 were more critical thinkers as compared to group 3, as group 2 had access to more forms of media, thus the value of

\footnotetext{
${ }^{105}$ W. James Potter, Media Literacy, 2001
} 
their media education is more. That is why they are more critical thinkers. From the results it can be seen that there is not a significant difference between group 1 and 2, strong and moderate media literate people, but there is a different between group 2, moderate media literate people (78\%) and group 3, low media literate people (67\%). Also there is a difference between group 1 (74\%) and group 3 (67\%), but the difference between moderate media literate people and low media literate people is more significant that the difference between group 1, strong media literate and group 3, low media literate.

There was insignificant difference in the results of males and females. This proves that development of critical thinking skills is based upon the reason mentioned above rather than on gender. The hypothesis that among media literate people those who have shaped their media habits over the years are more critical thinkers as compared to those who have not shaped their media habits over the years is correct but with a few exceptions as development of critical thinking skill depends on a combination of factor that include frequency of exposure to media, content, amount and awareness of the information they watch, read and listen.

\section{Conclusion}

Media literacy is an interesting and broad topic. The way people analyze, interpret and evaluate the messages that come from the media makes people a more active receiving audience and more conscious about what is happened around them. Media literacy should be studied in a range of contexts. For example, media literacy in education could explore what teachers teach in their classrooms and what techniques they should use to make students aware of the good and bad messages and how they teach them how to construct and deconstruct messages from the media. The study of sociological and political aspects is also very important in understanding how people become critical and 
active citizens. When they watch political news, their critical thinking abilities will help them to understand how people are portrayed in the different kind of media.

Discussion(s) with the parents and peers is going to shape peoples' knowledge structures and beliefs about the real world and the media world that surrounds them. Mass media can make people more critical thinkers when the context of the information received from the media is well used and understandable. Teachers and parents play a fundamental role in relation to educating kids and monitoring their use of mass media. Studying different kinds of media and what information is more beneficial and informative is going to help children to be more analytical in the way they speak, write and analyze the information that surrounds them.

For future research it is important to do more in-depth interviews with students to find out what kind of information they read, watch and listen to and the relation between the content of the information and frequency of media use and their critical thinking skills. It is also important to do deep research media use, specific media goals, types of stories people read, the programs they watch and the programs they listen that could reveal patterns correlating to media literacy levels. 


\section{Bibliography}

Alterman, Eric. 2003. Collin Powell and the Power of Audacity. Journalism United States, Politics and Government (September): 1-2.

Bells, Steve. 2001. The Media and Politics: It's more than the News. USA Today Magazine (March):10.

Berkman, Ronald and Laura Kitch. Politics in the Media Age. New York: McGraw-Hill, 1986.

Bowden, Gary. 1997. Science, Society and the Human Genome Project (Film). Canadian Journal of Sociology (Spring): 2-4.

Considine, David.2002 .Media Literacy: National Developments and International Origins. Journal of Popular Film and Television (Spring): 2.

Cull, Nicholas. 2000 .Introduction. Historical Journal of Film, Radio and Television (August):227.

DeFleur, Melvin and Dennis Everette. Understanding Mass Communication. Boston: Houghton Mifflin Company, 1994.

Freedman, Jonathan L. Media Violence and Its Effect on Aggression. Toronto: 
University of Toronto Press, 2002.

Glantz, Stanton. 2003. Smoking in movies: a major problem and a real solution. Lancet (July):2.

Goodlad, Graham.2003.The media and British Politics in the Twentieth Century. Journal of Mass Media and Politics (September):6.

Goodale, Gloia. 1999. What is missing from this picture? Journal of Television (August):1.

Goldberg, Jonah. 2000. The Bankrupt State. National Review (September):47.

Grossberger, Lewis. 2003. The Curse of the Curse. Media Week (September):34.

Hammer, Rhonda and Douglas Kellner. 2000. Multimedia Pedagogy and Multicultural Education for the New Millennium. Journal of Religious Education (Fall):5-8.

Hobbs, Renne. 1998. Building Citizens Skills through Media Literacy Education. Journal of the Center of Media Literacy (September): 56-57.

Hovland, Carl Irving L. Janis and Harold H. Kelley. Communication and Persuasion. London: Yale University Press, 1953. 
Johnson, Lesley L. Media, Education and Change. New York: Peter Lang Publishing, Inc., 2001.

Kamalipour, Yahya R. and Theresa Carilli. Cultural Diversity and the U.S Media. New York, State University of New York Press, 1998.

Katz, Elihu and Paul F. Lazarfeld. Personal Influence: The Part Played by People in the Flow of Mass Communications. New York: Free Press, 1965.

Lapham, Lewis. 2002. Notebook. Harper’s Magazine (October):8.

Lawrence Grossberg, Ellen Wartella and D. Charles Whitney. Media Making: Mass Media in a Popular Culture. London: SAGE Publications, Inc, 1998.

Lawrence, Regina G.2001 Rethinking Media Politics and Public Opinion: Reactions to the Clinton-Lewinsky Scandal. Political Science Quarterly (Fall):1-3.

Lazarfeld, Paul Bernard Berelson, and Hauzet Gaudet. The people choice: How the voters Makes Up His Mind in a Presidential Election. New York: Columbia University Press, 1948.

Lowery, A. Shearon and Melvin L. DeFleur. Milestone in Mass Communication Research. N.Y: Longman, 1995. 
Mahomy, Roger. 1995. God and Hollywood. New Perspectives Quarterly (Spring): 4.

Marker, Lewis. 2003. Fighting Reality Securities. Data Publishing On Wall Street (July):3.

Medved, Michael. 2002. That is Entertainment? National Interest (Summer):5.

McQuail, Denis. Mass Communication Theory: an introduction. London: Sage Publications, 1994.

Mishra, Punyashloke Michael D. Nicholson and Steven K. Wojcikiewicz. 2001. Seeing ourselves in the computer: How we relate to technologies. Journal of Adolescent \& Adult Literacy (April): 5-7.

Potter, James. Media Literacy. London: SAGE publications, 1998.

Media Literacy. London : Sage, 2001.

Rogers and Shoemaker.Communication of Innovations. New York: the free press, 1971.

Routledge,Paul. 2003. The truth about political journalists. National Review July):14.

Samuelson, Robert J.2003. Adventure in Agelessness. Newsweek Article (November): 29. 
Silverblatt, Art. Media Literacy: Keys to interpreting media messages. Westport Conn: Praeger, 2001.

Smolin Luanne. 2003. Becoming literate in the technological age: New responsibilities and tools for teachers. Journal of Reading Teacher (March): 570.

Schwarz, Gretchen. 2003. Renewing the Humanities through Media Literacy. Journal of Curriculum and Supervision (Fall): 44-53.

Schechter, Danny. 2001. The Challenge Ahead. Journal of Politics (February): 1-2.

Thoman, Elizabeth .1999. Skill and Strategies for Media Education. Educational Leadership 56 (February): 50.

Valente, Thomas. Network models of the Diffusion of Innovation. New Jersey: The Hampton Press communication series, 1995.

Van Horn, Royal. 2002. Sex, Potato Chips, and Media Literacy. Journal of Technology (September): 2.

Williams, Bronwyn T.2003. What they see and what we get: Television and middle school writers. Journal of Adolescent \& Adult Literacy (April): 2-6. 
Wolffe, Richard. 2003. Bush’s News War. Newsweek (October):1-2.

Yosso, Tara. 2002. Critical Race Media Literacy: Challenging Deficit Discourse about Chicanas and Chicanos. Journal of Popular Film and Television (Spring):3-10.

Scharrer, Erica. 2002. Making a case for media literacy in the curriculum: Outcomes and assessment” Journal of Adolescent and Adult \& Adult Literacy (December): 354.

Hill, Susan and Gordon B. Lindsay. 2003. Using Health Infomercials to Develop Media Literacy Skills,” Journal of School Health (August 2003):2.

Hobbs, Renee. 1998. The Seven Great Debates in the Media Literacy Movement. Journal of Communication (Winter): 5-9.

Edgerton, Gary R. and Michael T. Marsden. 2002. Media Literacy and Education: The Teacher Scholar in Film and Television. Journal of Popular Film and Television (Spring): 1-5.

Quesada, Arli. 2000. The Media Literacy Imperative. Technology and Learning (October): 1-5. 


\section{Appendix A}

Question 14 - Newspaper

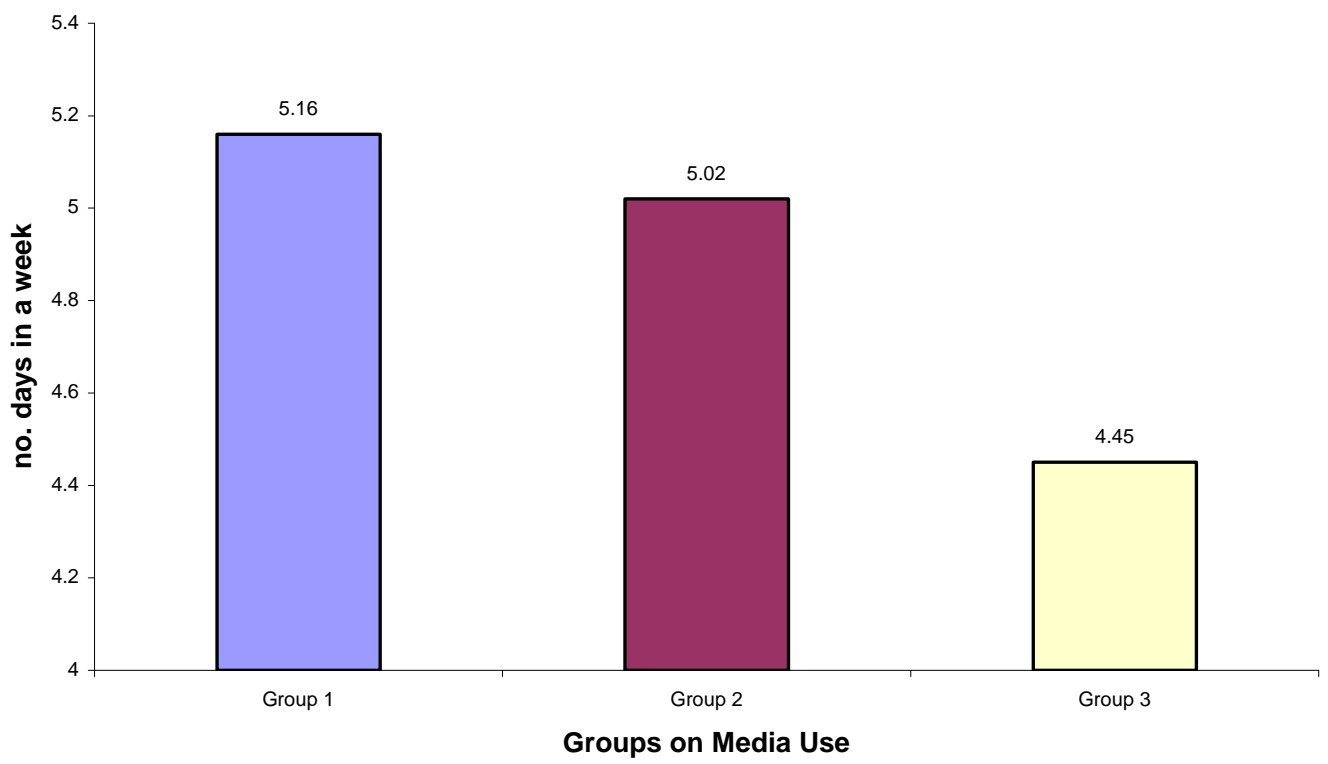

Figure1. Question 14. Frequency of reading newspapers without gender difference

Question 15 -Television

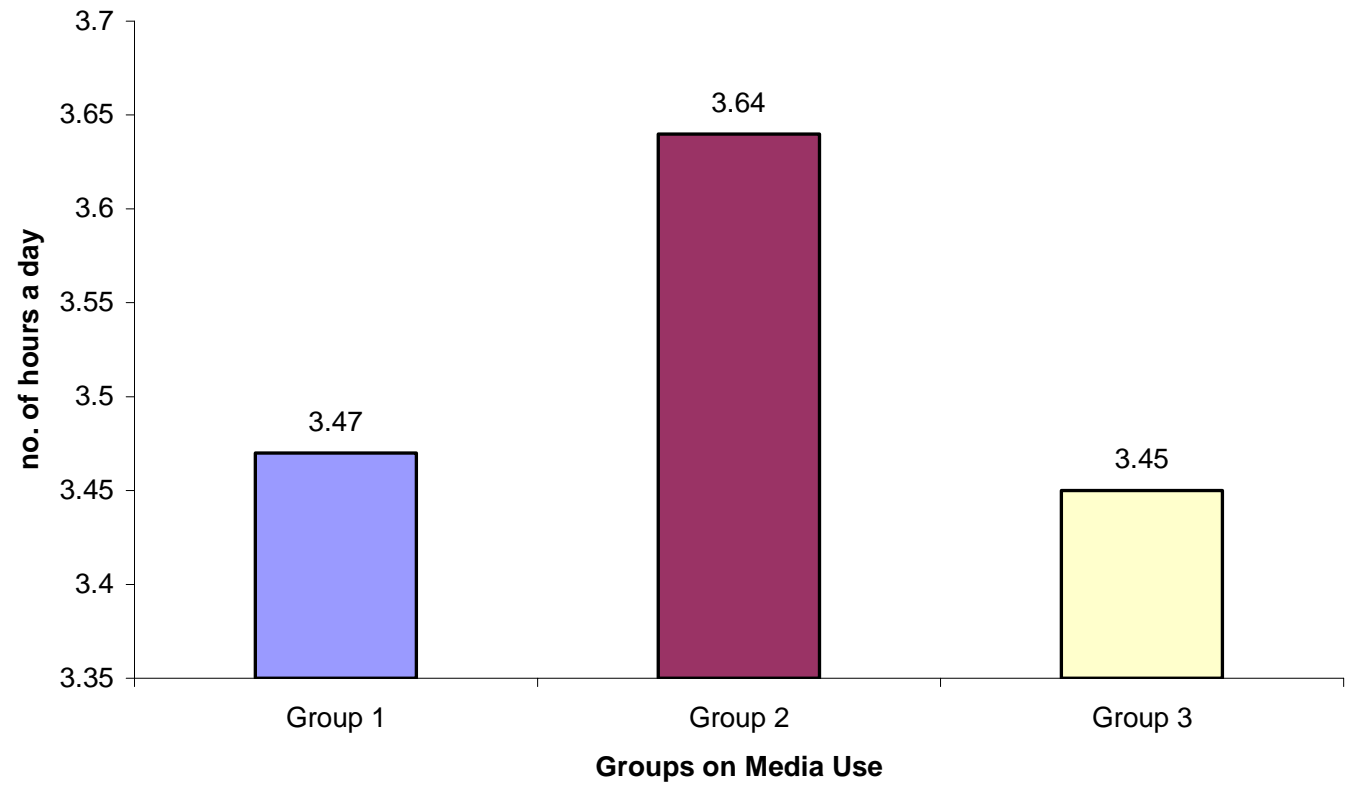

Figure 2. Question 15. Frequency of watching television without gender difference 
Question 16 - Internet

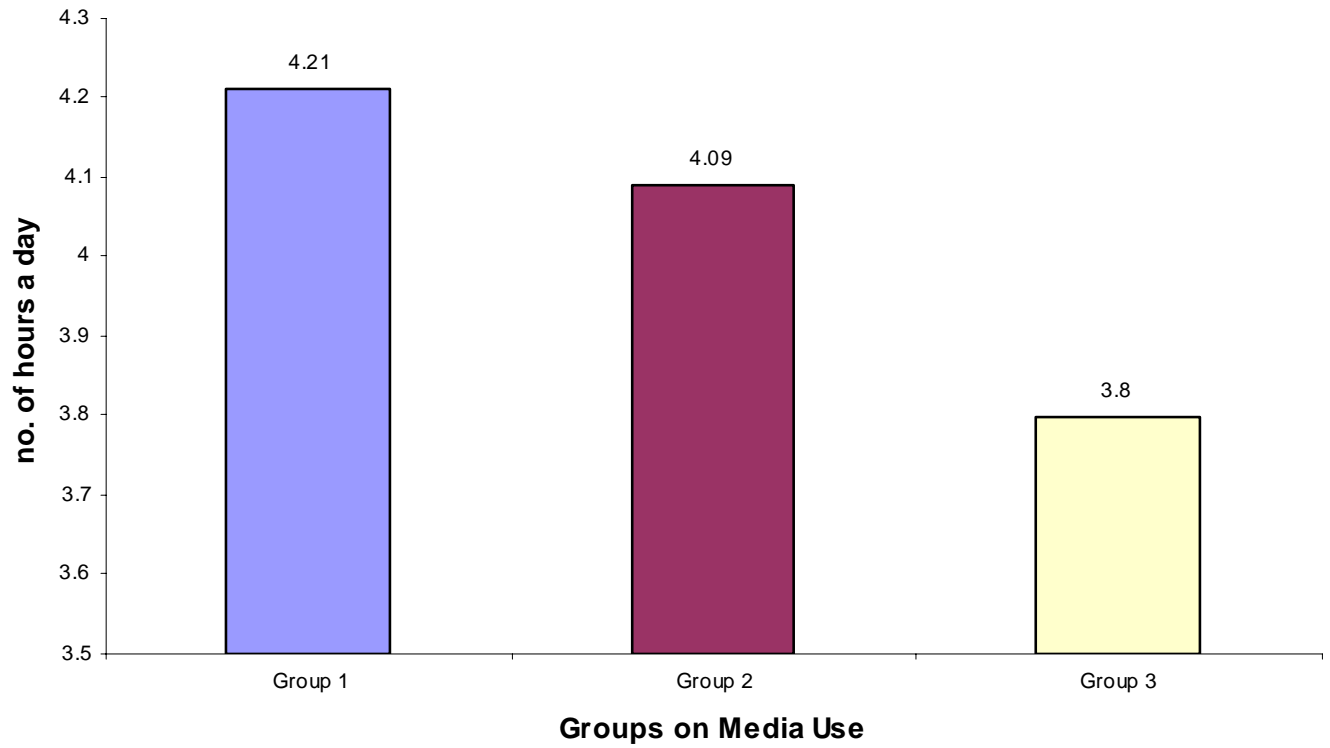

Figure3. Question 16. Frequency of using the Internet without gender difference

Question 14 - Newspaper(Gender)

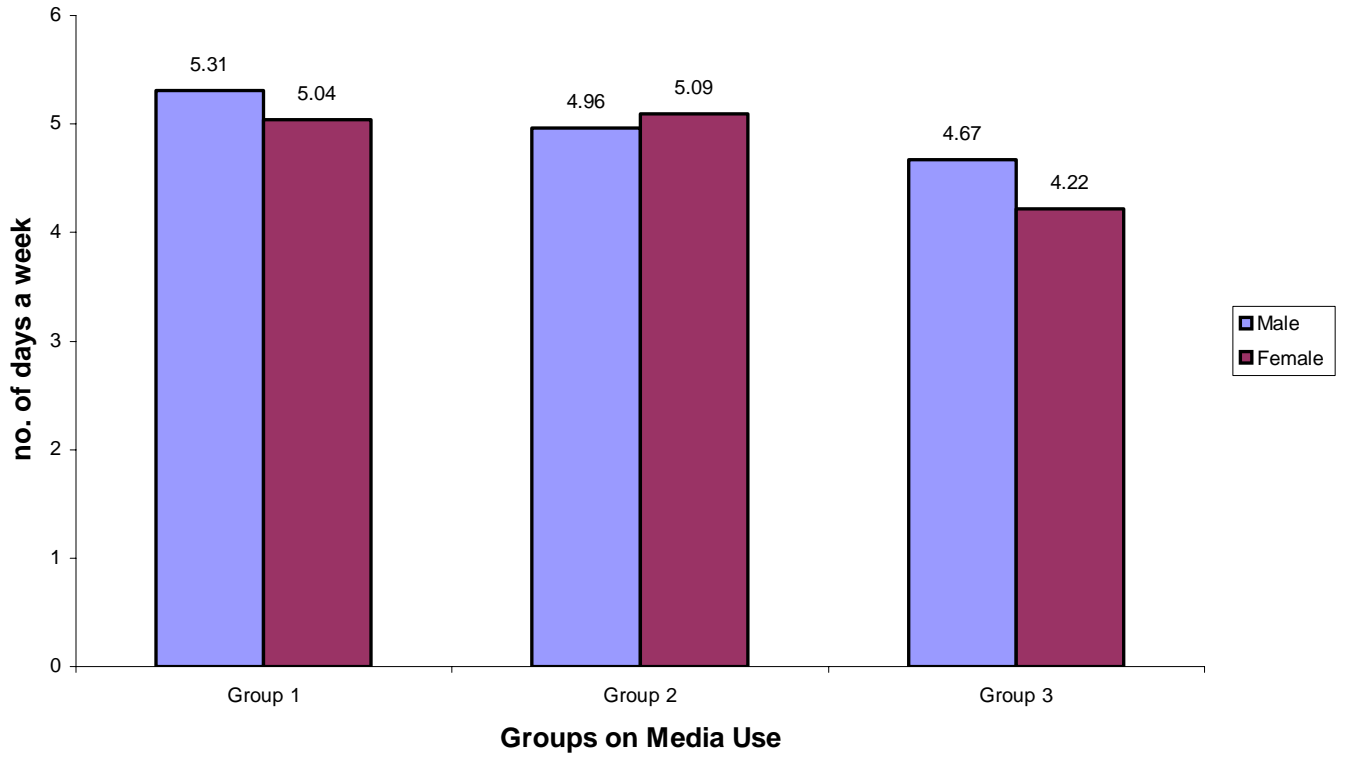

Figure 4. Question 14. Frequency of reading newspapers with gender difference 
Question 15 - Television(Gender)

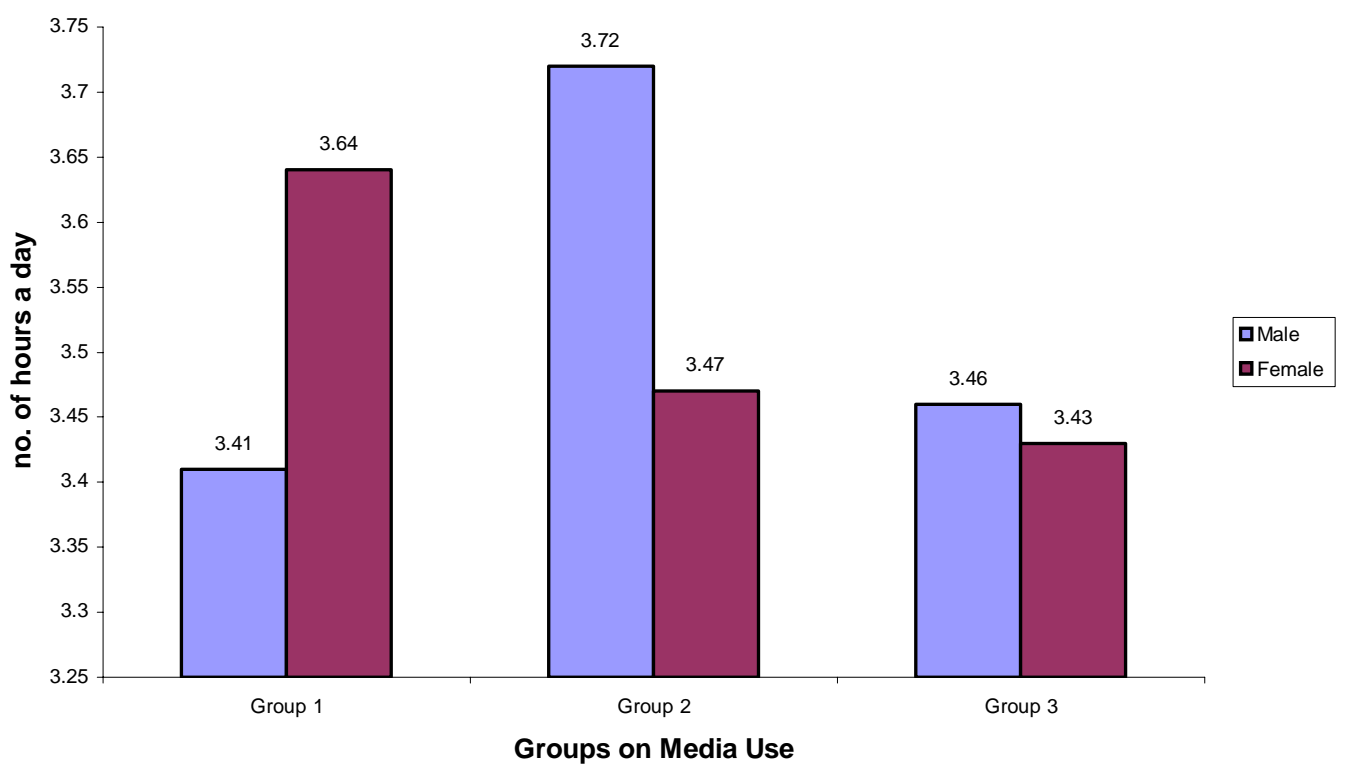

Figure 5. Question 15. Frequency of watching television with gender difference

Question 16 - Internet(Gender)

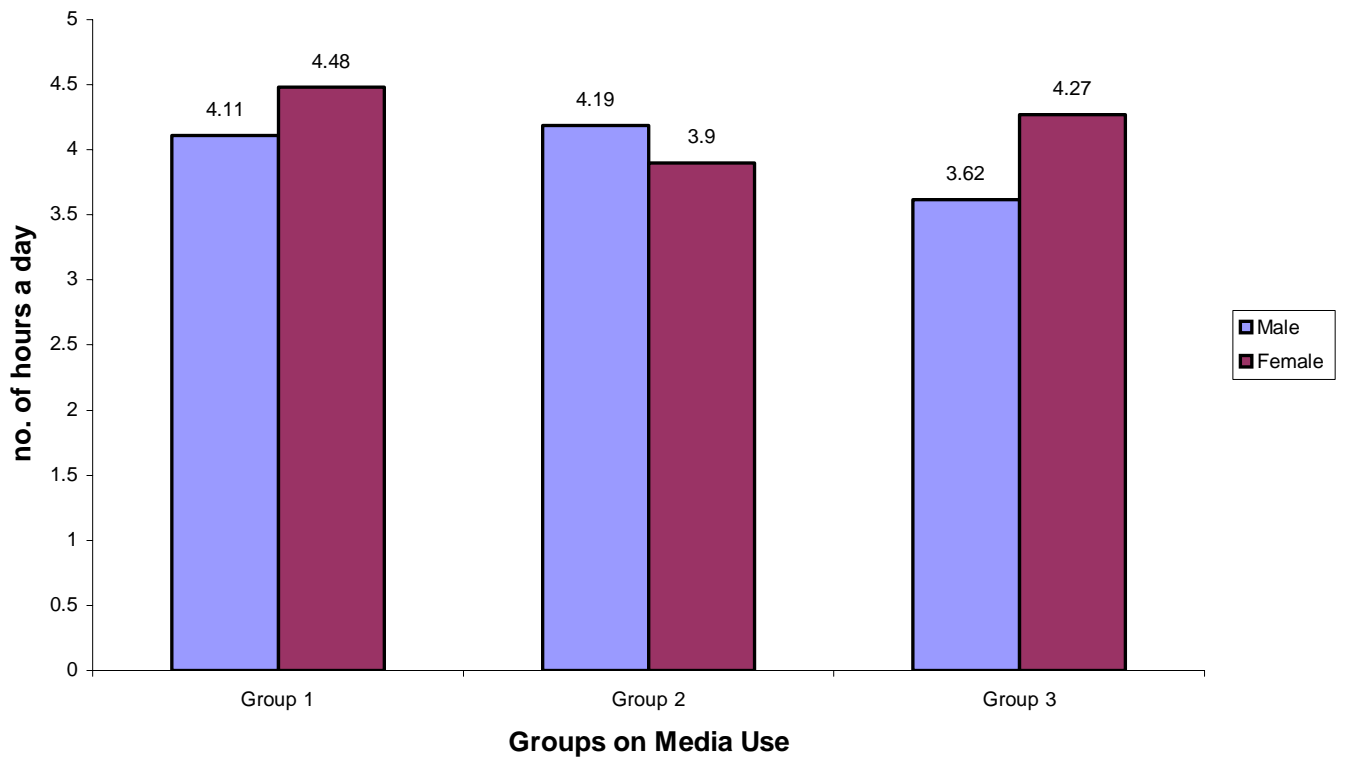

Figure 6. Question 16. Frequency of using the Internet with gender difference 
Question 18-Critical Thinking

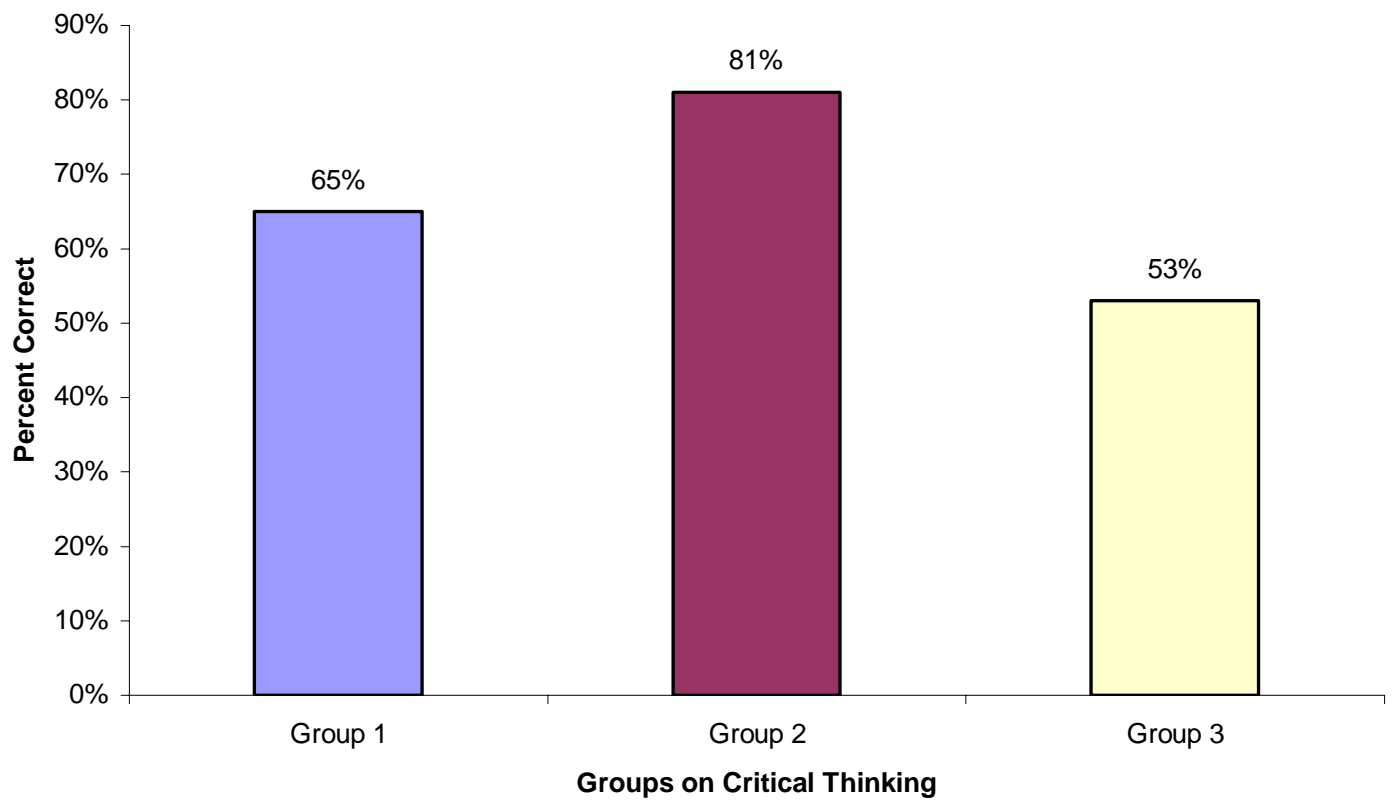

Figure 7. Question 18.Critical Thinking Questions: Figures without gender difference

Question 19-Critical Thinking

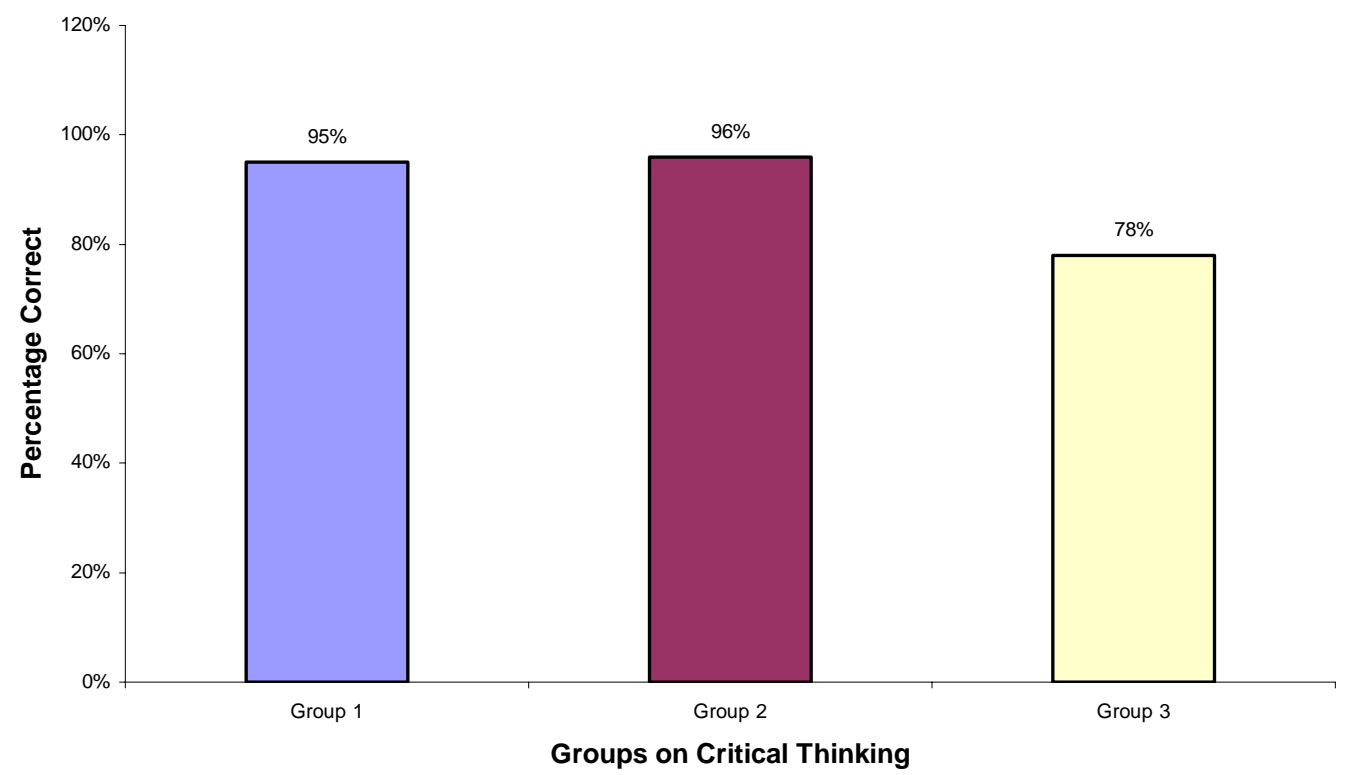

Figure 8. Question 19.Critical Thinking Questions: Figures without gender difference 
Question 20-Critical Thinking

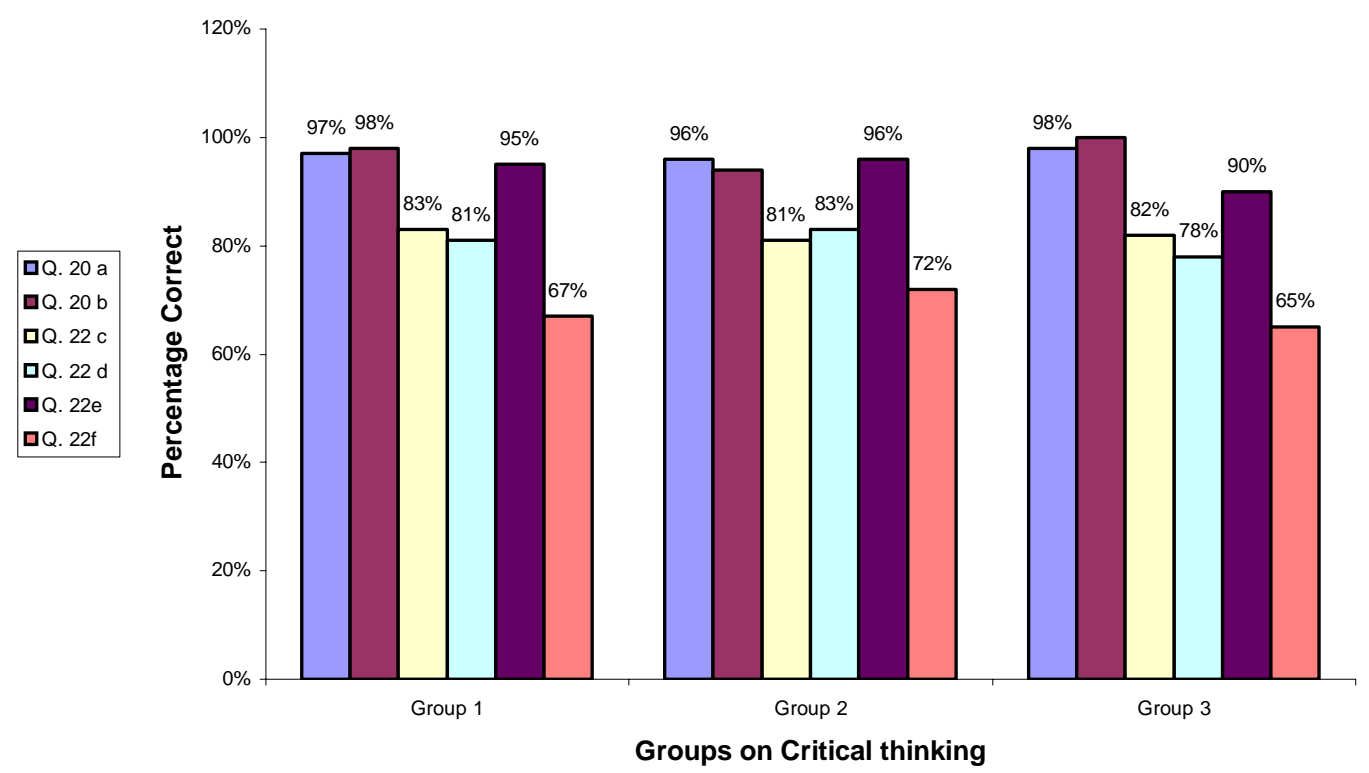

Figure 9. Question 20.Critical Thinking Questions: Figures without gender difference

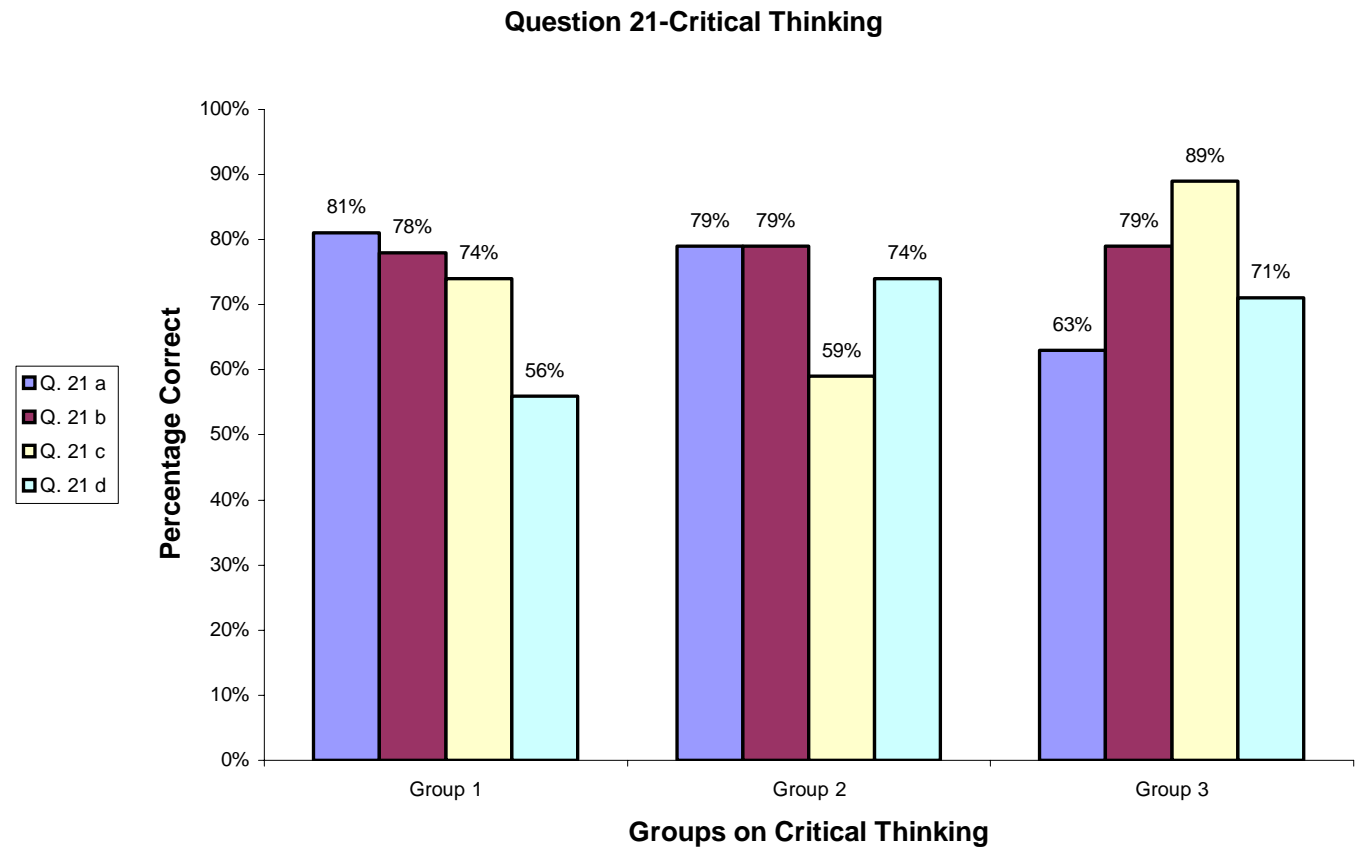

Figure 10.Question 21.Critical Thinking Questions: Figures without gender difference 
Question 22-Critical Thinking

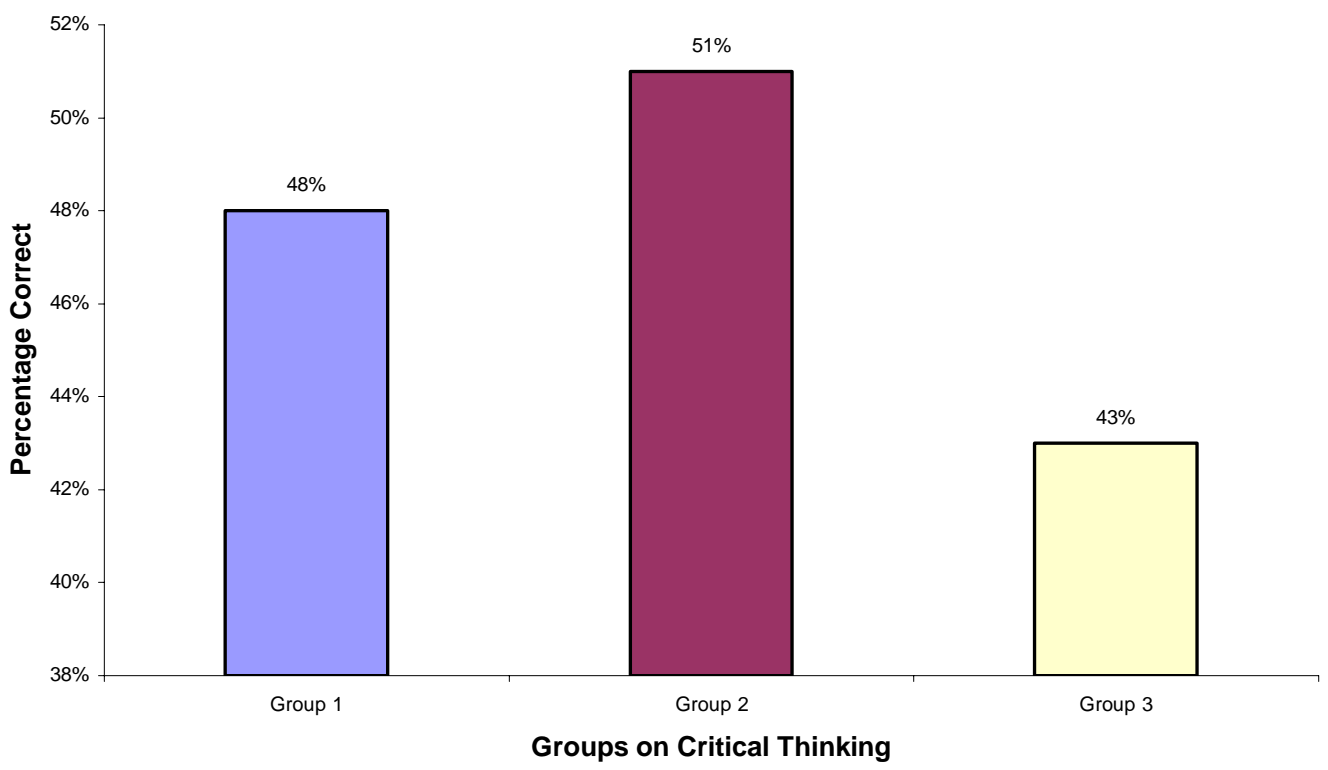

Figure 11.Question 22.Critical Thinking Questions: Figures without gender difference

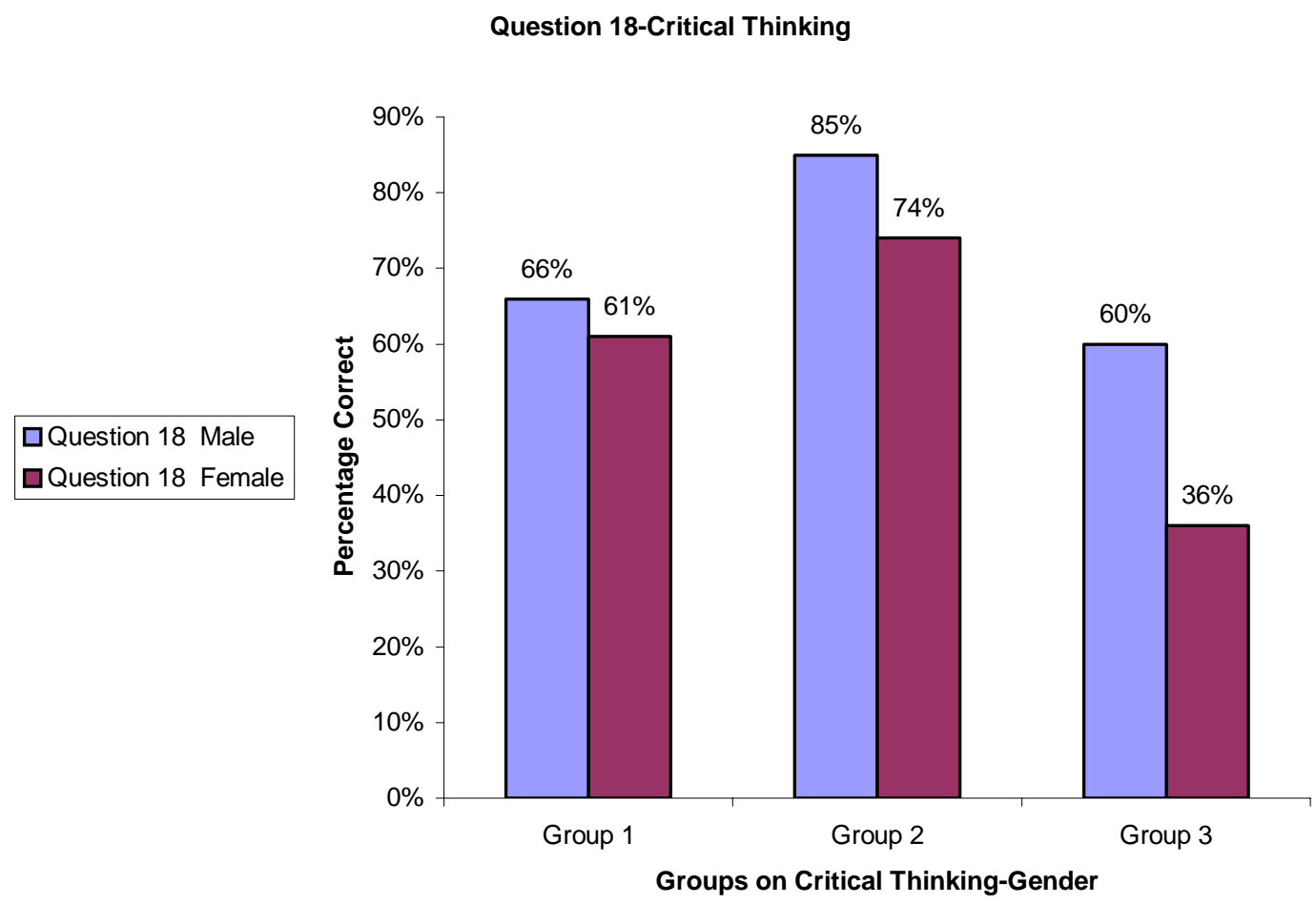

Figure 12. Question 18.Critical Thinking Questions: Figures with gender difference 


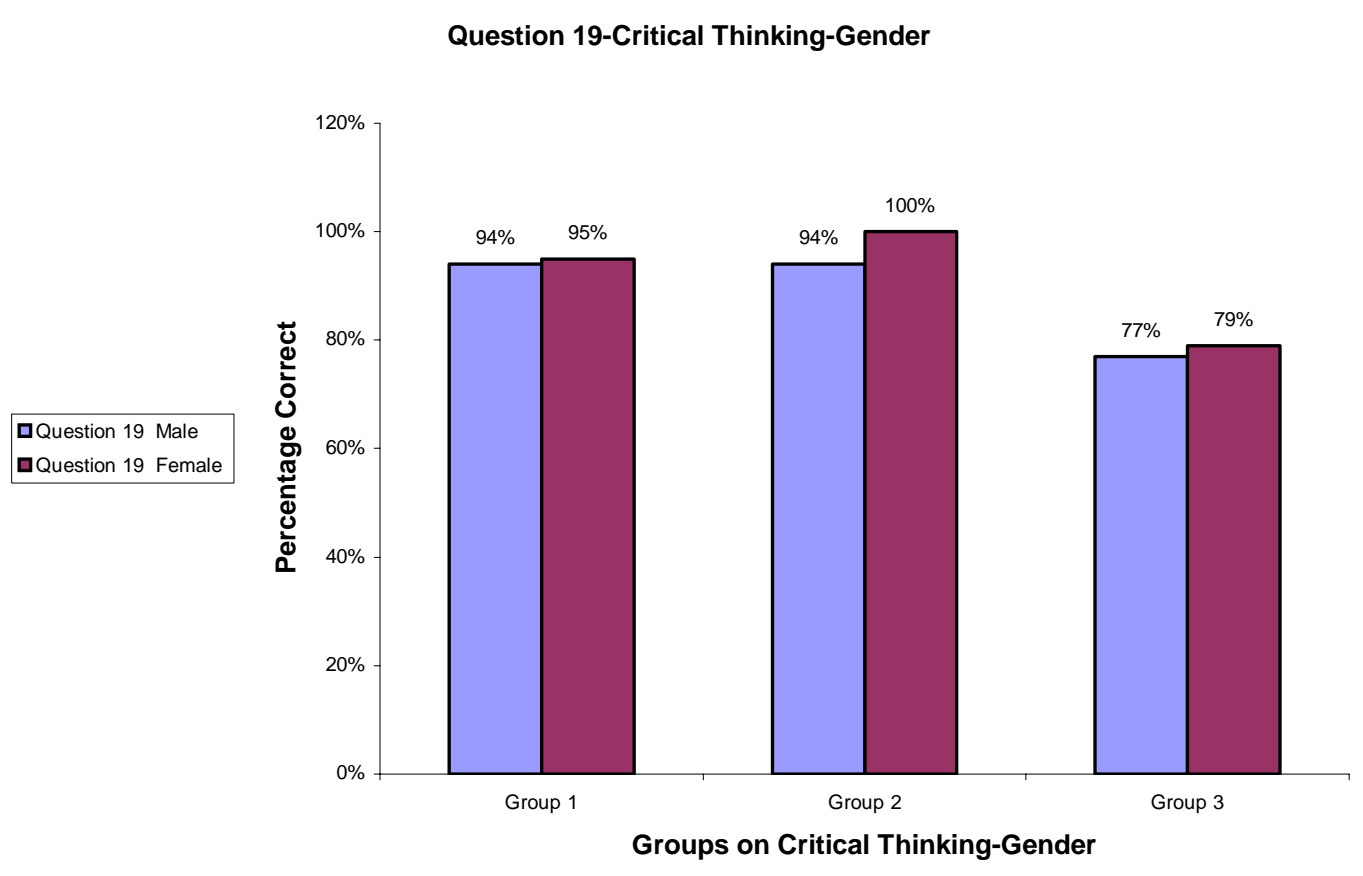

Figure 13. Question 19.Critical Thinking Questions: Figures with gender difference

Question 20 - a-Critical Thinking-Gender

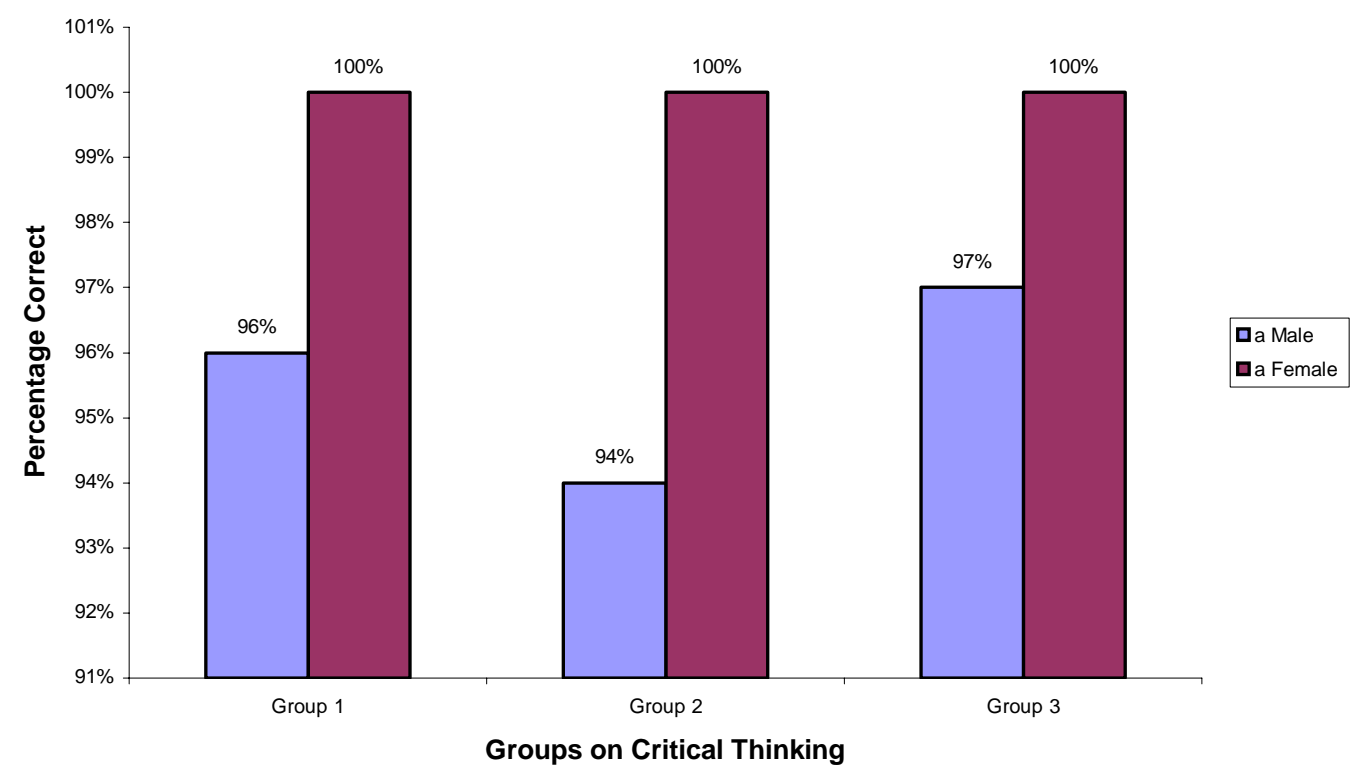

Figure 14. Question 20-a. Critical Thinking Questions: Figures with gender difference 
Question 20 - b-Critical Thinking-Gender

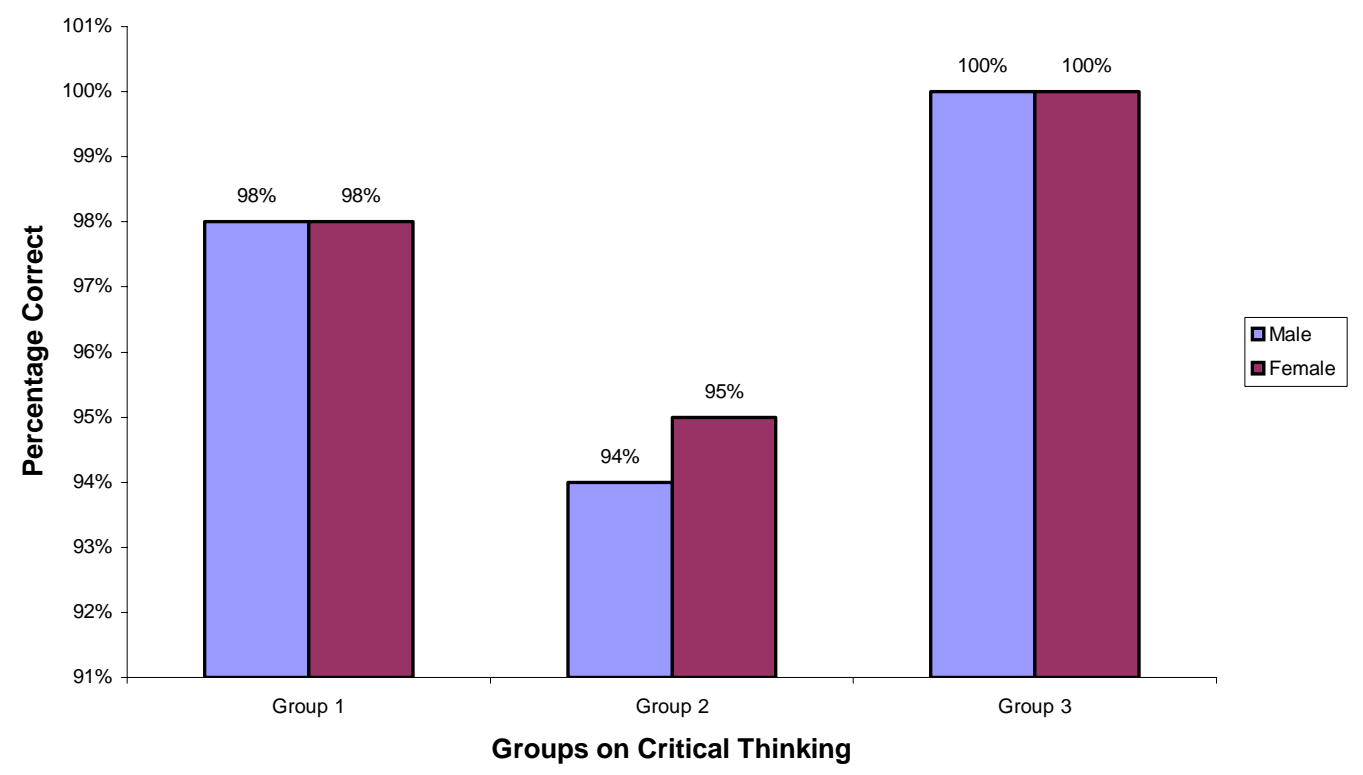

Figure 15.Question 20-b. Critical Thinking Questions: Figures with gender difference

Question 20 - c-Critical Thinking-Gender

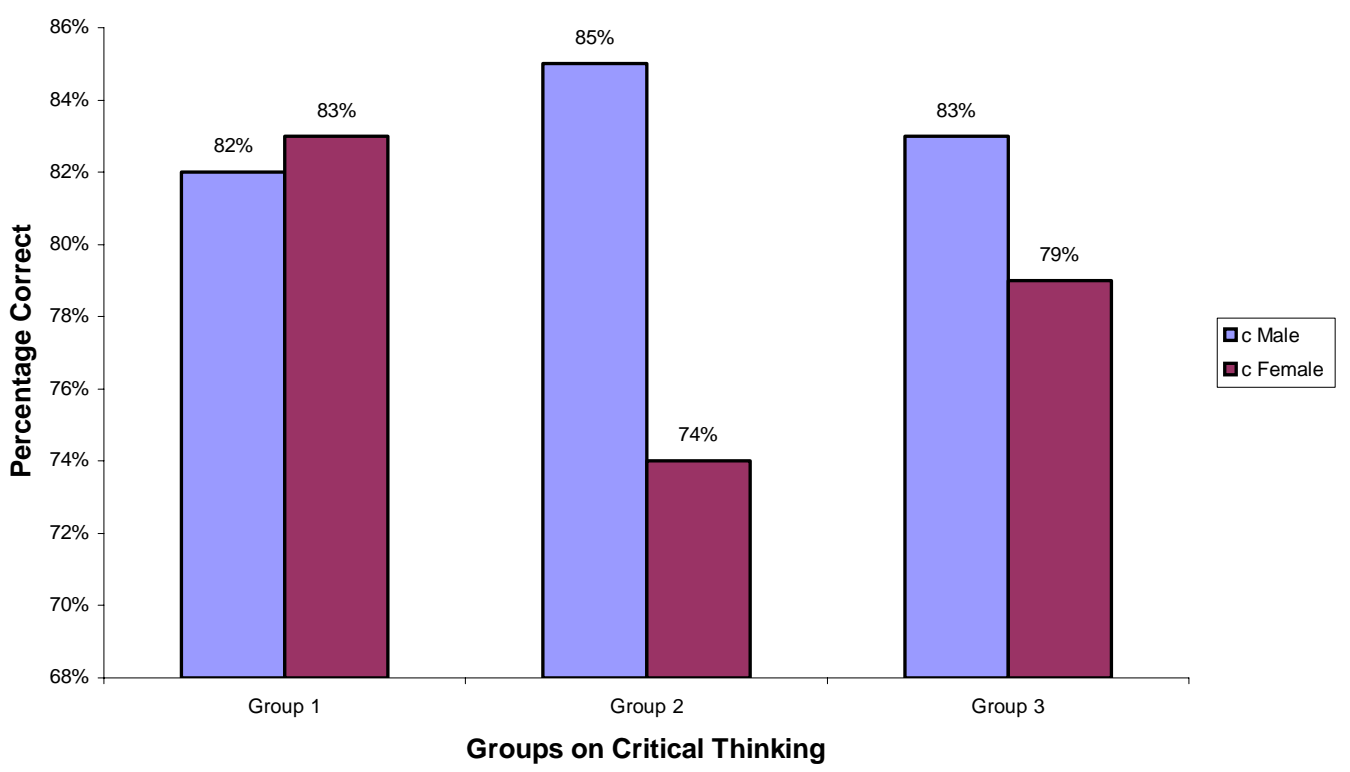

Figure 16.Question 20-c. Critical Thinking Questions: Figures with gender difference 
Question 20 - d-Critical Thinking-Gender

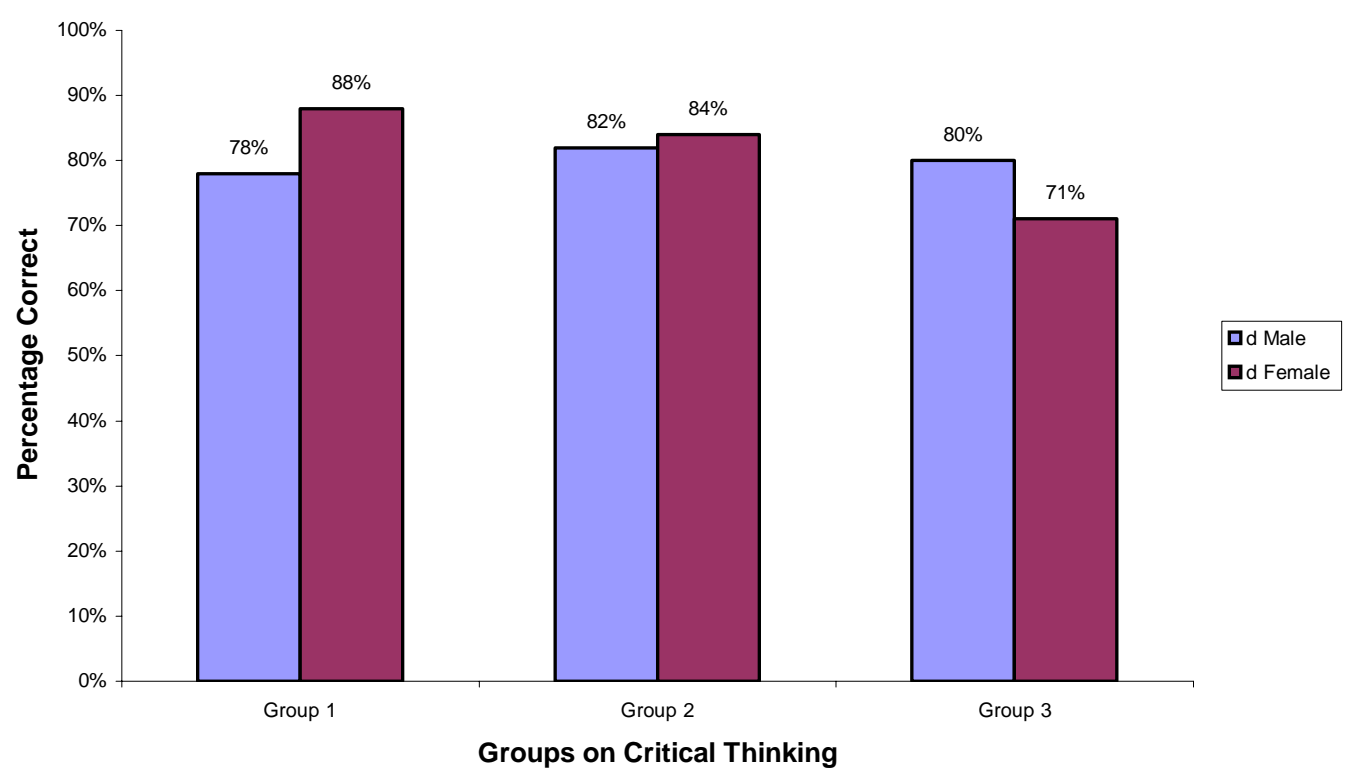

Figure 17.Question 20-d. Critical Thinking Questions: Figures with gender difference

Question 20 - e-Critical Thinking Gender

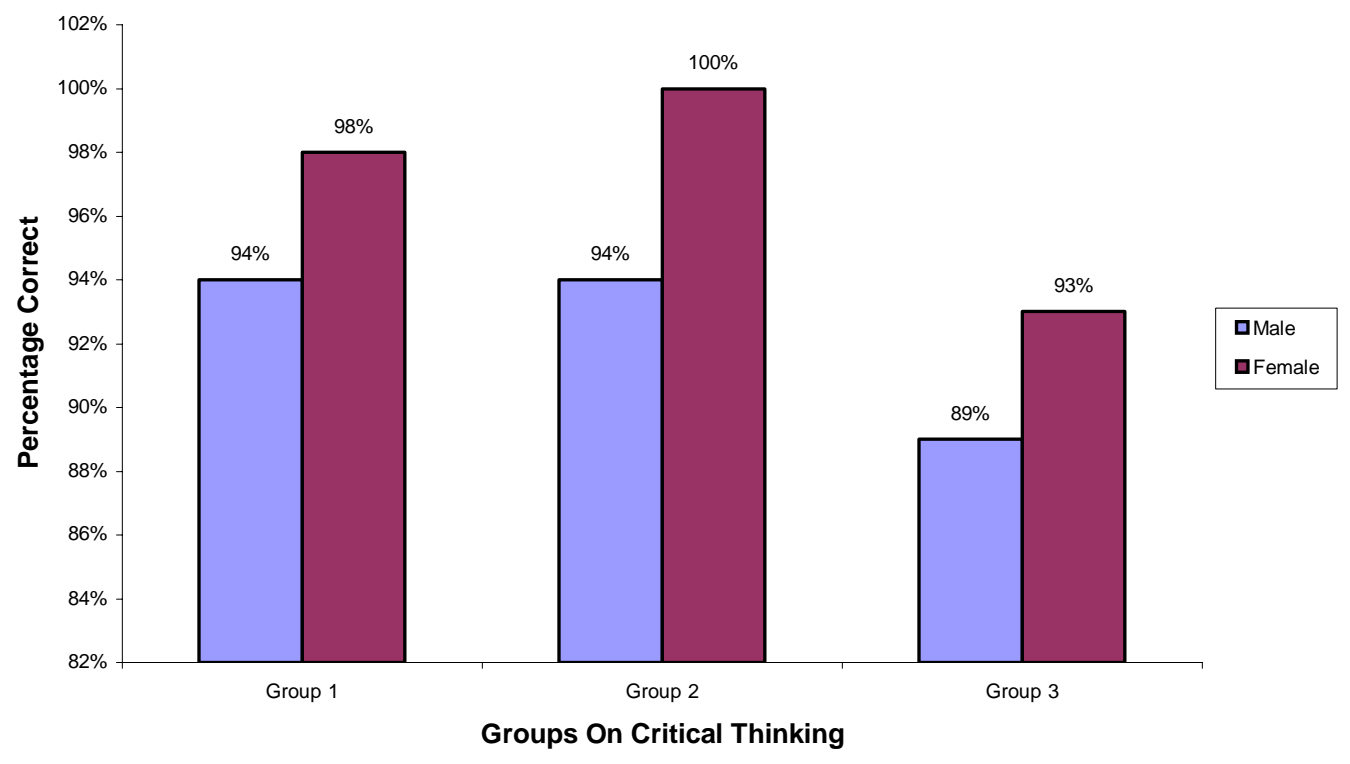

Figure 18.Question 20-e. Critical Thinking Questions: Figures with gender difference 
Question 20 - f-Critical Thinking-Gender

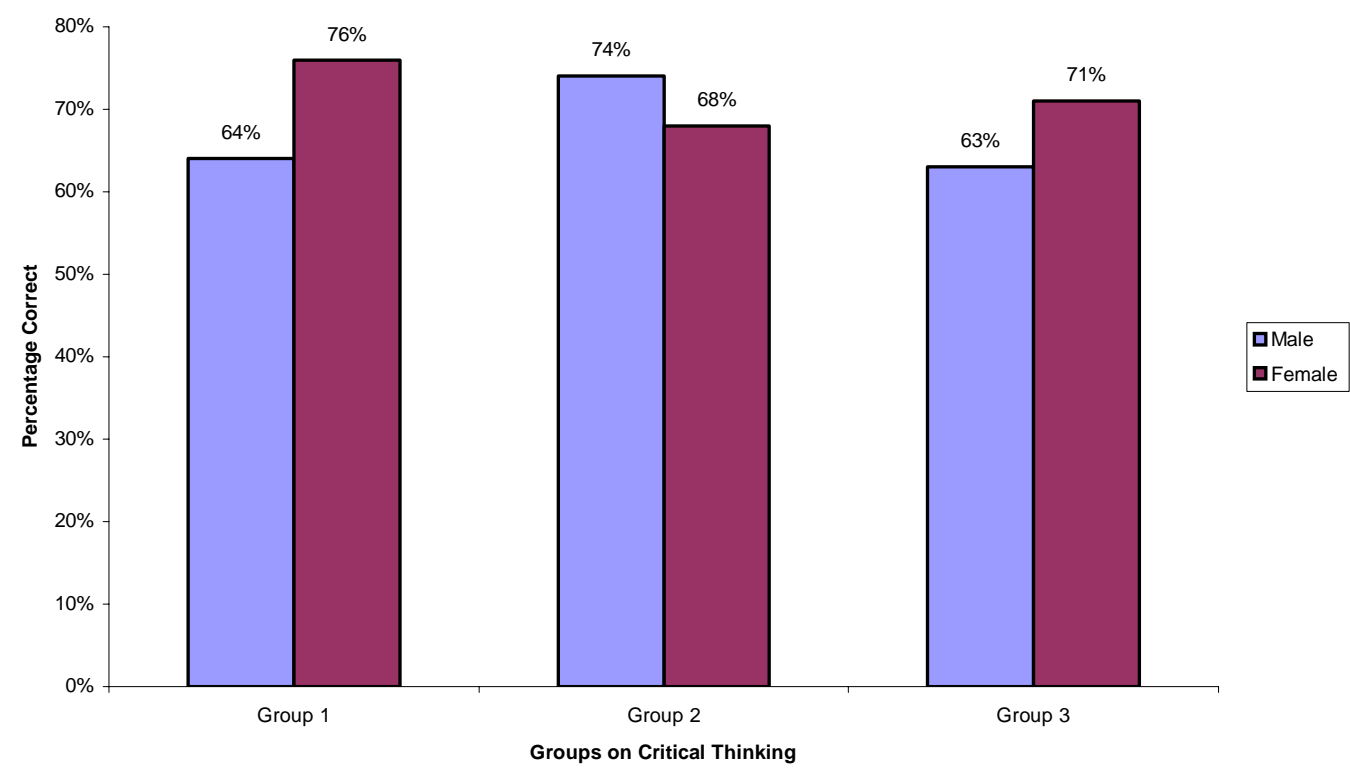

Figure 19.Question 20-f. Critical Thinking Questions: Figures with gender difference

Question 21 - a-Critical Thinking-Gender

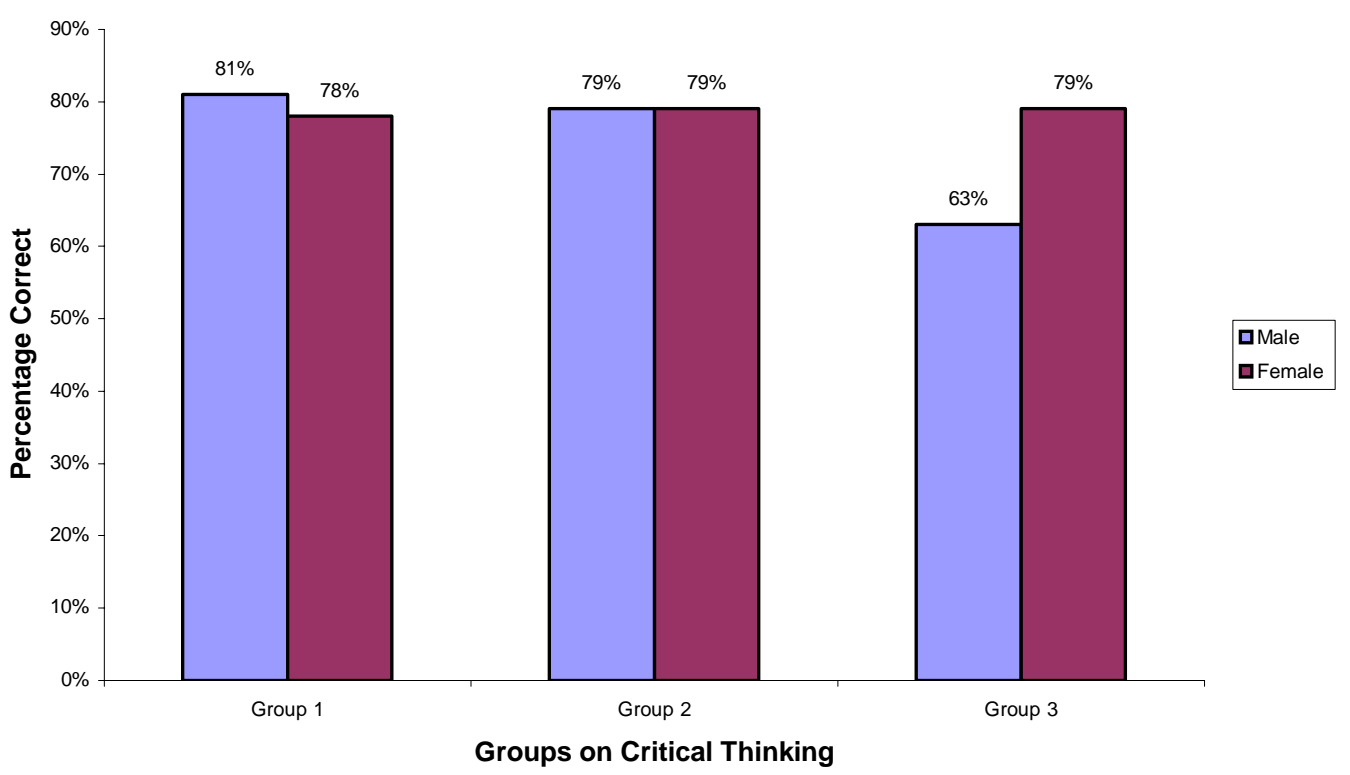

Figure 20.Question 21-a. Critical Thinking Questions: Figures with gender difference 
Question 21 b -Critical Thinking-Gender

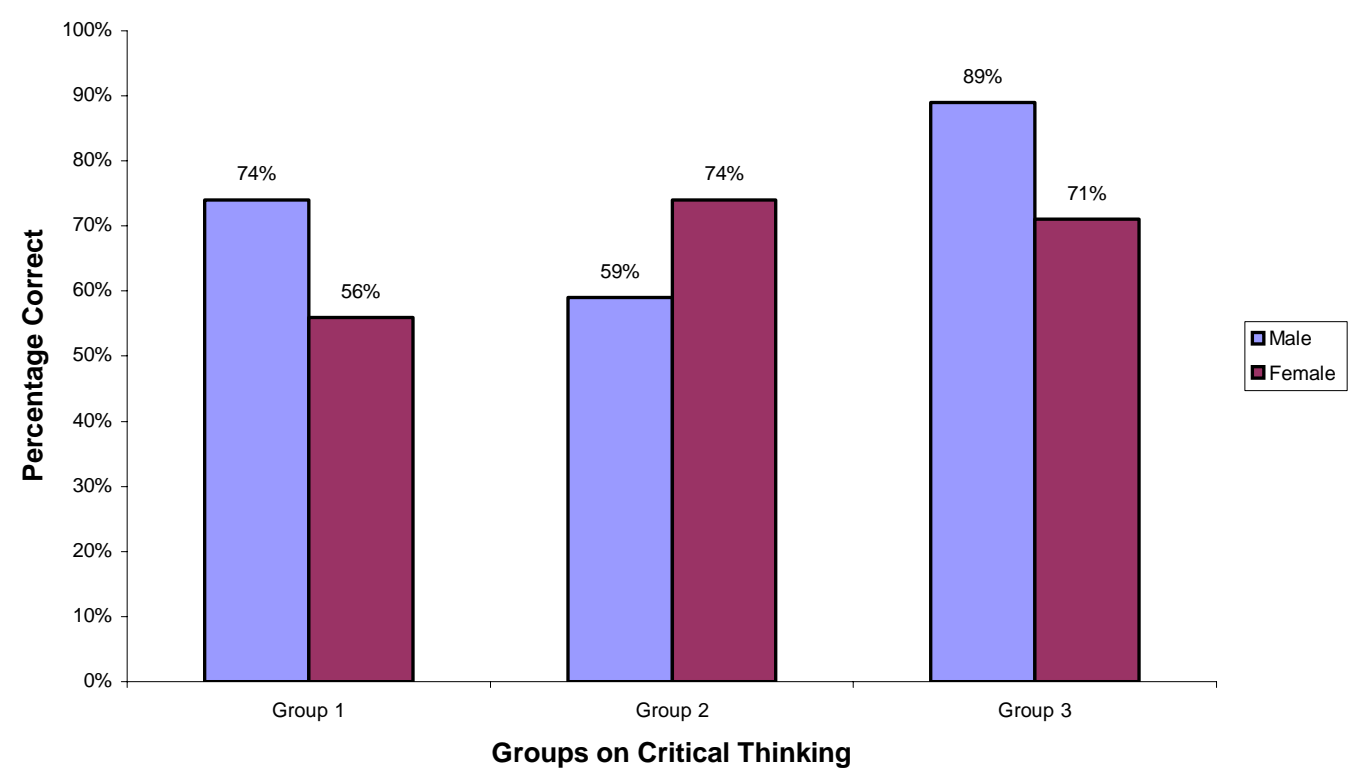

Figure 21.Question 21-b. Critical Thinking Questions: Figures with gender difference

Question 21 c-Critical Thinking-Gender

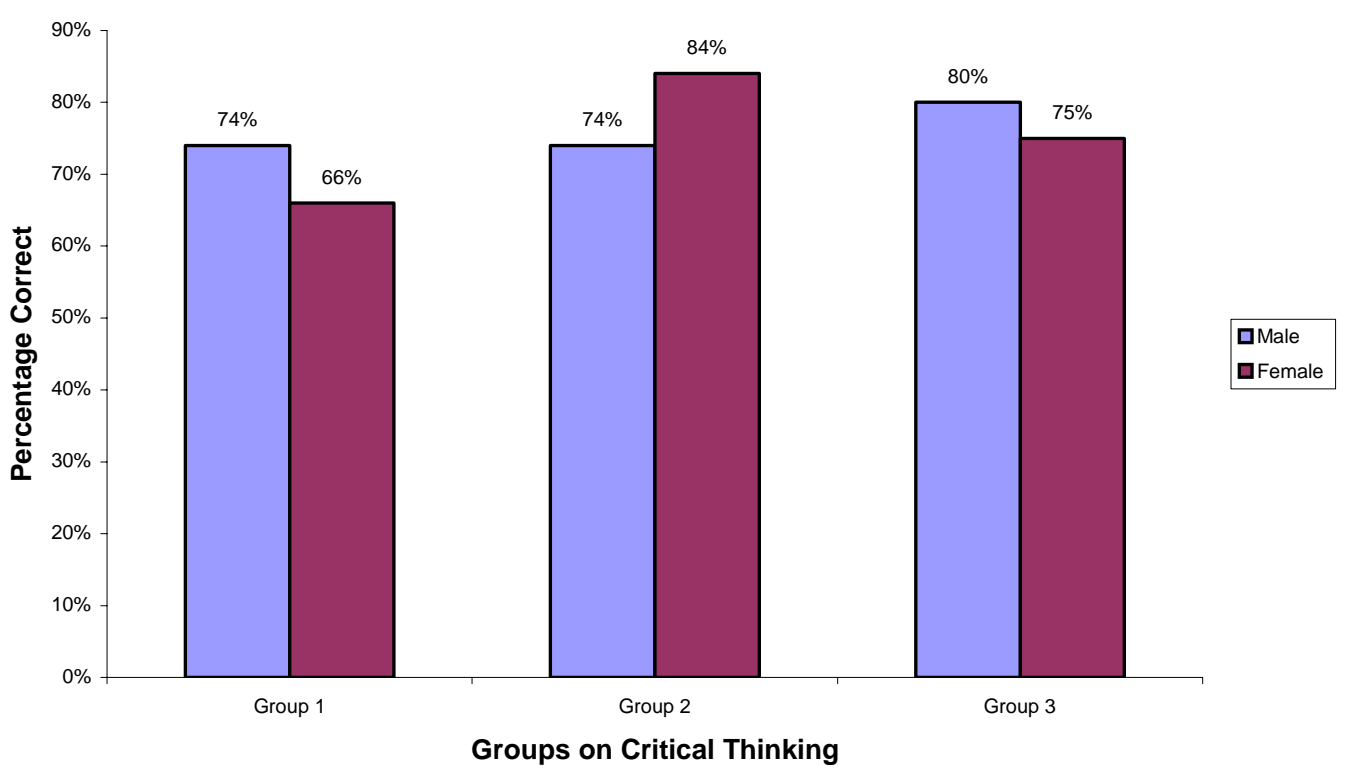

Figure 22.Question 21-c. Critical Thinking Questions: Figures with gender difference 
Question 21 d-Critical Thinking-Gender

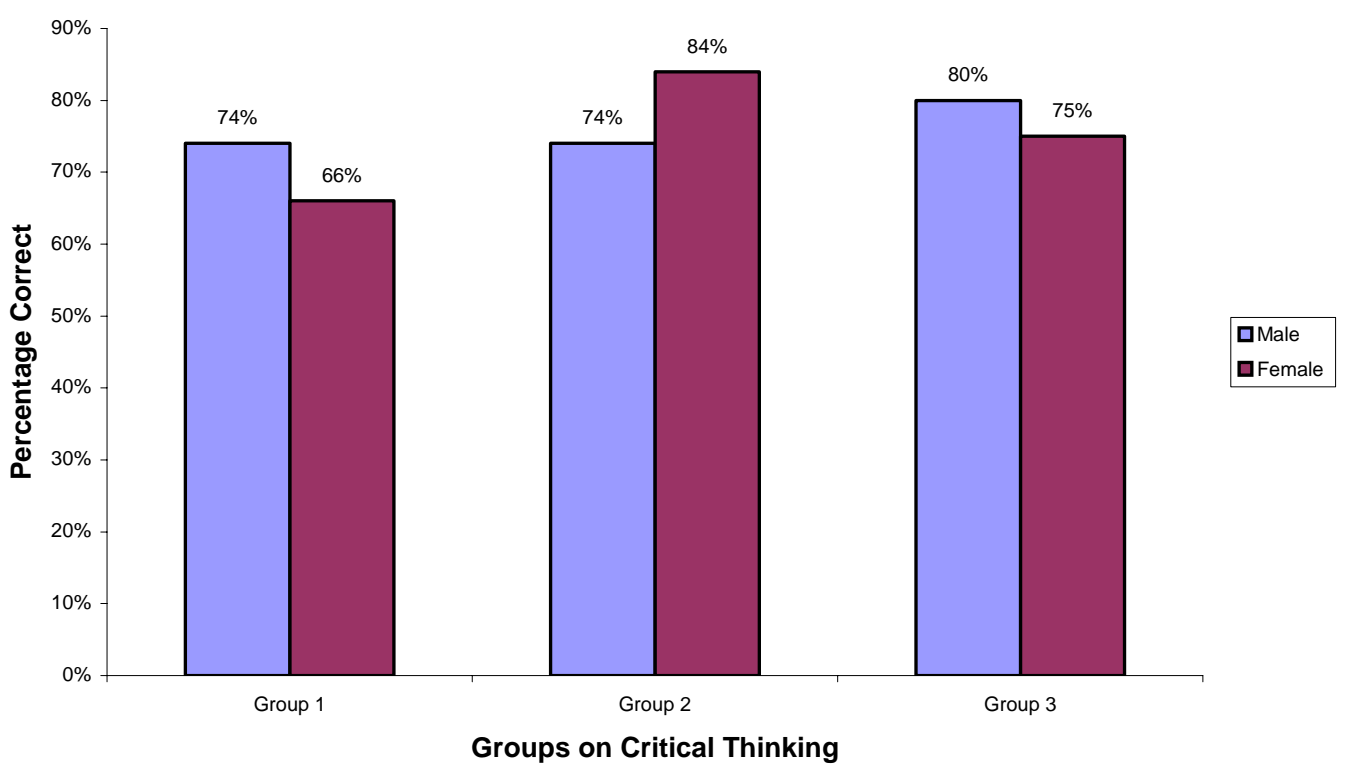

Figure 23. Question 21-d. Critical Thinking Questions: Figures with gender difference

Question 22- Critical Thinking

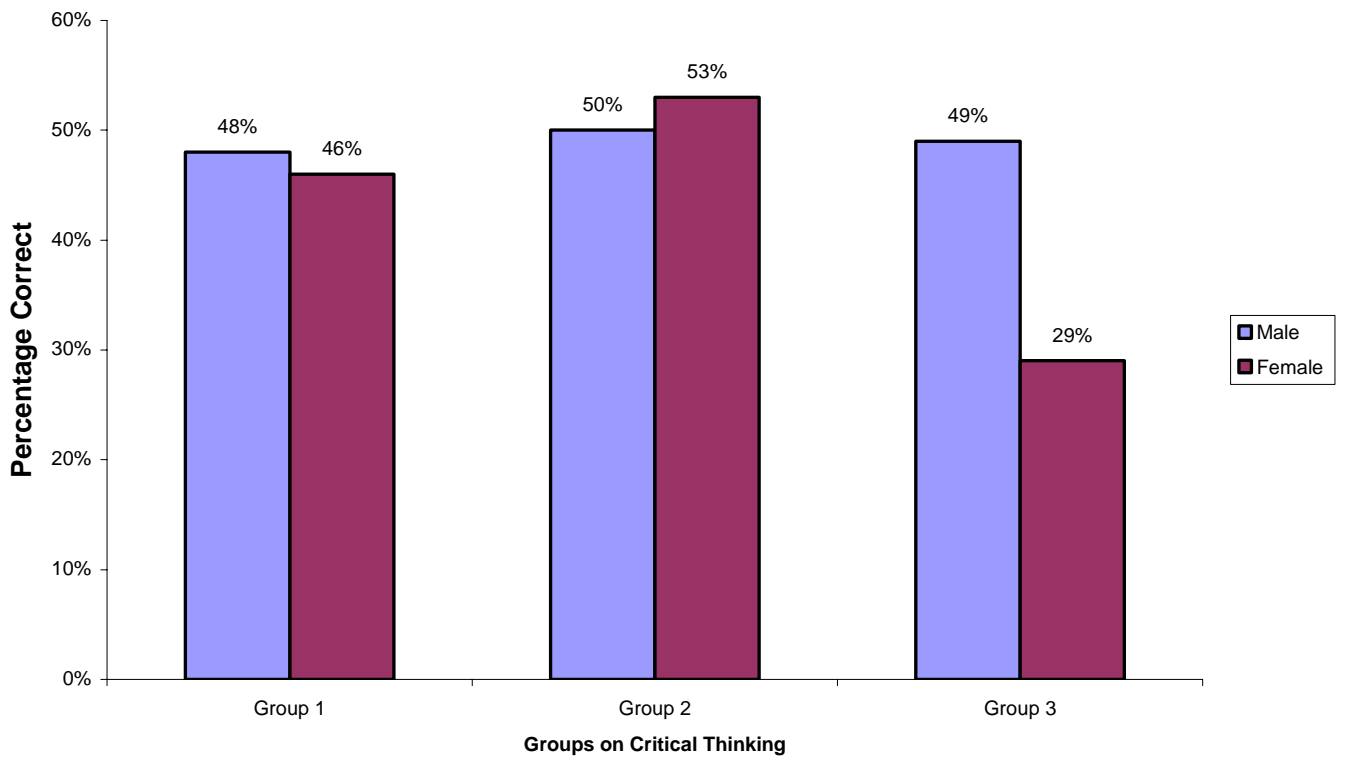

Figure 24. Question 22. Critical Thinking Questions: Figures with gender difference 


\section{Appendix B}

1) What is your sex?
a) Male
b) Female

2) What is your age?
a) Less than 18
b) $18-21$
c) $22-25$
d) $26-30$
e) More than 30

3) What is your race?
a) Caucasian
b) African-American
c) Hispanic
d) Asian
e) American Indian or Alaska native

4) What rank are you at WVU?
a) Freshman
b) Sophomore
c) Junior
d) Senior
e) Graduate or professional student

5) Tell me how frequently these forms of media were used to supplement your class learning when you were in elementary school?

Very frequently frequently infrequently rarely if ever

$\begin{array}{lllll}\text { a) Television } & 1 & 2 & 3 & 4 \\ \text { b) Newspapers } & 1 & 2 & 3 & 4 \\ \text { c) Magazines } & 1 & 2 & 3 & 4 \\ \text { d) Radio } & 1 & 2 & 3 & 4 \\ \text { e) Internet } & 1 & 2 & 3 & 4\end{array}$


6) How frequently were these forms of media used to supplement your class learning when you were in high school?

Very frequently frequently infrequently rarely if ever

$\begin{array}{lllll}\text { a) Television } & 1 & 2 & 3 & 4 \\ \text { b) Newspapers } & 1 & 2 & 3 & 4 \\ \text { c) Magazines } & 1 & 2 & 3 & 4 \\ \text { d) Radio } & 1 & 2 & 3 & 4 \\ \text { e) Internet } & 1 & 2 & 3 & 4\end{array}$

7) How frequently are these forms of media used to supplement your class learning in college?

Very frequently frequently infrequently rarely if ever

$\begin{array}{lllll}\text { a) Television } & 1 & 2 & 3 & 4 \\ \text { b) Newspapers } & 1 & 2 & 3 & 4 \\ \text { c) Magazines } & 1 & 2 & 3 & 4 \\ \text { d) Radio } & 1 & 2 & 3 & 4 \\ \text { e) Internet } & 1 & 2 & 3 & 4\end{array}$

8) Tell me how frequently when you were in elementary school that you discussed with your parents information that you:

Very frequently frequently infrequently rarely if ever
a) Read in the newspaper
b) Watched on television
12
12
c) Read in a magazine
12
d) Listened to on radio
1
e) Accessed in the Internet
1

$\begin{array}{ll}3 & 4 \\ 3 & 4 \\ 3 & 4 \\ 3 & 4 \\ 3 & 4\end{array}$

9) Tell me how frequently when you were in high school that you discussed with your parents information that you:

Very frequently frequently infrequently rarely if ever
a) Read in the newspaper
1
b) Watched on television
1
c) Read in a magazine
12
d) Listened to on radio
1
e) Accessed in the Internet
1

$\begin{array}{lll}2 & 3 & 4 \\ 2 & 3 & 4 \\ 2 & 3 & 4 \\ 2 & 3 & 4 \\ 2 & 3 & 4\end{array}$

10) Tell me how frequently now that you discuss with your parents information that you: 
Very frequently frequently infrequently rarely if ever
a) Read in the newspaper
1
2
3
b) Watched on television
1
c) Read in a magazine
1
d) Listened to on radio
1
e) Accessed in the Internet
1
2
2
2
34
34
34

11) Tell me how frequently when you were in elementary school that you discussed with your friends information that you:

Very frequently frequently infrequently rarely if ever
a) Read in the newspaper
1
b) Watched on television
2
3
4
c) Read in a magazine
1
1
2
d) Listened to on radio
e) Accessed in the Internet
1
2
2
2
34
$3 \quad 4$

34

$\begin{array}{lll}2 & 3 & 4\end{array}$

12) Tell me how frequently when you were in high school that you discussed with your friends information that you:

Very frequently frequently infrequently rarely if ever
a) Read in the newspaper
1
b) Watched on television
1
c) Read in a magazine
1
d) Listened to on radio
1
e) Accessed in the Internet
1

2
2
2
2
2

$\begin{array}{ll}3 & 4 \\ 3 & 4 \\ 3 & 4 \\ 3 & 4 \\ 3 & 4\end{array}$

13) Tell me how frequently now that you discuss with your friends information that you:

Very frequently frequently infrequently rarely if ever
a) Read in the newspaper
12
2
34
b) Watched on television
1
c) Read in a magazine
1
d) Listened to on radio
1
e) Accessed in the Internet
1

34

34

$3 \quad 4$

14) How many days in a week do you read a newspaper, either its printed form or online: a) 0 

b) 1
c) 2
d) 3
e) 4
f) 5
g) 6
h) 7

15) How many hours in a day do you watch TV?
a) I do not watch.
b) Less than 1 hour
c) 1 to 2 hours
d) 2 to 3 hours
e) 3 to 4 hours
f) More than 4 hours per day.

16) How many hours in a day do you use the Internet?

1) I never use the Internet

2) Less than 1 hour per day

3) 1 to 2 hours per day

4) 2 to 3 hours per day

5) 3 to 4 hours per day

6) More than 4 hours per day.

7) I never use the Internet.

17) The following are some questions about the decisions that the media such as TV, radio, newspapers, magazines and Internet help you with? On a scale of 1 to 5 where, 1 represents "very helpful” and 4 represents "not helpful at all”. How much media help do you receive in taking the following decisions:

$\begin{array}{lcccc} & \text { VH } & \text { H } & \text { SH } & \text { NH at all } \\ \text {-Presidential elections } & 1 & 2 & 3 & 4 \\ \text {-Buying a house } & 1 & 2 & 3 & 4 \\ \text {-Organizing a research project } & 1 & 2 & 3 & 4 \\ \text {-Investing money } & 1 & 2 & 3 & 4 \\ \text {-Which book to buy } & 1 & 2 & 3 & 4\end{array}$

18) The following question present an argument where P1 represents "premise 1" and P2 represents "premise 2" and C represents " the conclusion”, can you tell if the conclusion of these premises is valid or invalid?

P1) Every Roman emperor before Constantine was a pagan. 
P2) Julian was a Roman Emperor

C) Julian was a pagan

a) Valid

b) Invalid

19) What in your opinion is the best conclusion for this premise?

"In some countries men have the right to confine their wives forcibly; in other countries they do not”

a) Conclusion: human beings do not have the same rights at all places and at all times.

b) Conclusion: the conservative claim is that throughout history, in all times and places, people fundamentally have the same rights.

20) Two statements are incompatible if it is impossible for both of them to be true (if they are incompatible, it may or may not be possible for both to be false). Which of the following pairs of statements are incompatible?

Compatible Incompatible
a) Some hamster are black. All hamsters are white. 1 2
b) Some hamster are black. Some hamsters are white. 12
c) Some hamsters are black. Most hamsters are not black.
1 2
d) Some hamsters are black. All hamsters are black. 12
e) No hamsters are black. Most hamsters are black. 1 2
f) Most hamsters are black. Many hamsters are white.
1 2

21) Hard generalization is one that is correctly conveyed by using a quantifier such as “all”, “every”, “each” and “no”. Soft generalization uses “most” in some examples or does not express a specific quantifier. Can you tell which of these sentences represent a hard generalization and which represent soft generalization?

Hard Soft

a) If John is under 18, then he cannot legally purchase alcohol in the UK $\quad 12$ 
b) If that is a scorpion, then it is poisonous. $\quad \begin{array}{ll}1 & 2\end{array}$

c) If that wine is not French, then it is probably not overpriced. $\quad \begin{array}{ll}1 & 2\end{array}$

d) That picture is not likely to be an oil painting if it is not Dutch or Flemish. 12

22) This sample question consists of a sentence with two blanks, each blank indicating that something has been omitted. Following the sentence are six lettered words. Choose the word or set of words for each blank that best fits the meaning of the sentence as a whole.

Early___ of hearing loss is___ by the fact that other senses are able to compensated for moderate amounts of loss, so that people frequently do not know that their hearing is imperfect.
a) discovery..... Indicated
b) development... prevented
c) detection..... complicated
d) treatment.... facilitated
e) incidence.... corrected 